\title{
Visualization of flowfield modification by RCS jets on a capsule entry vehicle
}

\author{
P.M. Danehy ${ }^{*}$, J.A. Inman ${ }^{\dagger}$, D.W. Alderfer ${ }^{\ddagger}$, G.M. Buck ${ }^{\S}$ \\ NASA Langley Research Center, Hampton VA, 23681-2199 \\ B. Bathel $^{* *}$ \\ University of Iowa, Iowa City, IA, 52242
}

\begin{abstract}
Nitric-oxide planar laser-induced fluorescence (NO PLIF) was used to visualize the flow on the aft-body of an entry capsule having an activated reaction control system (RCS) jet. A capsule shape representative of the Apollo command module was tested in the NASA Langley Research Center's 31-Inch Mach 10 wind tunnel facility. Two different RCS converging-diverging nozzle designs were used. One nozzle had a conical diverging section while the other had a bell-shaped contoured section followed by a conical section. The two nozzles had area ratios of $\mathbf{1 3 . 4}$ and $\mathbf{2 2 . 5}$ respectively. Both conical nozzle sections had halfangles of $10^{\circ}$. Low- and high-Reynolds number cases were investigated by changing the tunnel stagnation pressure from 350 psi to 1300 psi, resulting in freestream Reynolds numbers of 0.55 and 1.8 million per foot respectively. For both cases, three different jet plenum pressures were tested (nominally 56, 250 and 500 psi). Images were also acquired for conditions where the jets were issuing into low pressure static gas with the wind tunnel not operating. A single vehicle angle-of-attack of $24^{\circ}$ was investigated. Visualizations of the flow issuing from the two nozzle shapes were markedly different near the nozzle internal to the RCS jet plume, while relatively similar in structure on the outer edges of the plume. Visualizations produced by seeding pure NO from the vehicle's forebody show that operation of the RCS jet forces the aft shear layer to become turbulent and deflects the shear layer away from the vehicle significantly, with deflection angle increasing with jet pressure.
\end{abstract}

\section{Introduction}

$\mathrm{R}$ eaction control system (RCS) jets are used by capsule entry vehicles to steer and orient vehicles during entry. The primary force generated by the jet is parallel to the axis of the jet. However, several secondary effects can alter the net force applied to the vehicle, thereby changing the desired force and moment vectors. For example, the RCS jets can directly impact vehicle surfaces or perturb shock waves, expansions and shear layers. Consequently, the flow direction can be altered, resulting in sometimes undesired aerodynamic interactions. Furthermore, the RCS jets can cause localized heating on the capsule which could lead to vehicle failure if the jets and thermal protection system are not designed appropriately. Thus, it is critical to understand and to be able to accurately predict RCS jets and their aerodynamic and aerothermal interactions with the vehicle. Surface measurements such as heat transfer gauges, phosphor thermography or temperature sensitive paint (TSP) can be used in wind tunnel tests to quantify and understand the surface heating on the vehicle. These can be compared with computational models for the flow to validate the computations.

However, if experiments and computations disagree, it is highly desirable to have an off-body flowfield visualization to suggest how the computations could be modified in order to match the experiment (or alternately, to determine whether the experiment had undesired artifacts not modeled by the codes). Schlieren flow visualization, which is inexpensive, easy to use and is already implemented in many facilities, is unlikely to provide good visualization of RCS jets in hypersonic flow facilities. This is due to the fact that hypersonic wake flows generally

\footnotetext{
${ }^{*}$ Research Scientist, Advanced Sensing and Optical Measurement Branch, MS 493, AIAA Associate Fellow.

${ }^{\dagger}$ Research Scientist, Advanced Sensing and Optical Measurement Branch, MS 493, AIAA Member.

* Research Scientist, Advanced Sensing and Optical Measurement Branch, MS 493

${ }^{\S}$ Research Scientist, Aerothermodynamics Branch, MS 408A.

** Graduate Student, Mechanical Engineering, NASA LARSS Student, AIAA Student Member
} 
are very low density. Previous work in the same facility ${ }^{1}$ showed that RCS jets were not visible in schlieren photography for the conditions tested. However, even if schlieren could provide measurements of RCS jets, highly three dimensional flows such as yaw and roll jets would not be clearly resolved because the method is a pathaveraged measurement. Finally, with schlieren, the model partially blocks the path of the light so the jet flow of interest may be in shadow.

Planar laser-induced fluorescence (PLIF) can provide spatially resolved 2- and 3-dimensional measurement of RCS jet shapes as shown in past work using PLIF of iodine $\left(\mathrm{I}_{2}\right)^{2}$ and nitric oxide (NO). ${ }^{1}$ In the present experiment, the jet is seeded with a few percent of NO and a planar sheet of ultraviolet laser light excites this NO. The excited NO emits fluorescence that is imaged by a camera oriented perpendicular to the laser sheet. If the position of this laser sheet is scanned, volumetric data can be obtained. Since the incoming light and camera are at right angles to each other, PLIF can be used to measure in cavities, corners and on the sides of capsule flows. NO PLIF is sensitive and can provide high signal-to-noise images over a wide range of gas densities, including the low densities experienced in hypersonic flow facilities. The images have flow-stopping time resolution $(1 \mu \mathrm{s})$ and spatial resolution sufficient to image turbulent structures in the flow.

This paper describes the use of NO PLIF to study pitch RCS jets on a capsule similar to the Apollo command module (ACM). Two different nozzle shapes were investigated. NO was added to the RCS jets for jet visualization and, in separate runs, NO was supplied to a port on the forebody heat shield to provide aft-body shear-layer visualization. This paper focuses on the fluid mechanical aspects of these RCS jet flows. A related paper by Inman et al. $^{3}$ provides a detailed description of the use of the PLIF measurement technique in this experiment as well as a broader survey of the different flowfields studied in this test, including roll and yaw RCS jets on the ACM, yaw jets on the Orion crew module and a simulated ablation measurement on the forebody heatshield. Another related paper by Watkins et al. ${ }^{4}$ describes pressure and temperature sensitive paint measurements obtained as part of this same test and at the same operation conditions as the PLIF data, but not obtained simultaneously. Finally, a paper by Buck et al. ${ }^{5}$ describes the model construction and shows comparisons between selected PLIF, PSP and TSP results.

\section{Experiment and Analysis Description}

The experiments were performed in the 31-Inch Mach 10 Air Tunnel at the NASA Langley Research Center. The test apparatus consisted of three main components: the test articles, the wind tunnel facility and the PLIF system. The analysis involved image processing and rendering in a three-dimensional software environment. These are summarized briefly in this section with references describing where more details can be found.

\section{A. Test Article}

In a recent experiment ${ }^{6}$ it was demonstrated that hypersonic wind tunnel capsule models could be built rapidly, inexpensively, and with internal plumbing appropriate for seeding NO, using a stereo lithography apparatus (SLA). However, the forebody capsule heating was excessive for the materials used in that test, resulting in model degradation. For the present test, a capsule model was fabricated using a steel heatshield, plenum and sting. SLA was used to produce the rest of the test article including the capsule afterbody and RCS jet nozzles. The model was designed with interchangeable parts so that different nozzle and afterbody shapes and configurations could be tested. The design and manufacture of this model is detailed by Buck et al. ${ }^{5}$ In the present paper, only results obtained using the ACM configuration are described and only the pitch RCS jet is investigated. Two nozzle contours are studied. Figure 1 shows the two nozzle designs. The first has a 0.088 -inch long conical converging section with a 22.7 degree half angle, a 0.055 -inch long straight throat with a diameter of 0.0275 inches and a 10 degree half angle conical diverging section which is scarfed at the end. This nozzle hereafter is referred to as the cone nozzle. The second nozzle had an identical converging section and throat but the diverging section was a bell-shaped contoured nozzle that transformed into a conical nozzle with a 10 degree half angle. This nozzle hereafter is referred to as the bell nozzle. The cone nozzle had an exit-to-throat area ratio of 13.4, resulting in a Mach number of 4.3 at the exit (assuming isentropic flow of a perfect diatomic gas). The bell nozzle had an exit-to-throat area ratio of 22.5, resulting in a Mach number of 4.9 at the exit. The cone nozzle was based on the current design of the Mars Science Lab (MSL) RCS jets. ${ }^{7}$ The bell nozzle was designed to provide a larger area ratio over the same length as the cone nozzle. Both nozzles had larger area ratios and smaller exit angles than the prior RCS jet visualization tests ${ }^{1}$ performed in the same facility.

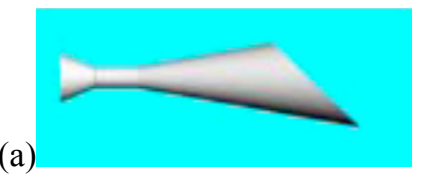

Figure 1. Nozzle Contours. The left figure (a) is the "cone" nozzle while (b) shows the "bell" nozzle. 


\section{B. Wind Tunnel, Operating Conditions, Mass Flow Control and Data Acquisition Systems}

The 31-Inch Mach 10 Air Tunnel is an electrically-heated blowdown facility located at NASA Langley Research Center in Hampton, Virginia, USA. Reference 8 details this facility, a brief summary of which is provided here. The facility has a nominal Mach number of 10 and a 31-inch square test section and operates on electrically heated, compressed air. Large windows, transparent in the ultraviolet down to approximately $190 \mathrm{~nm}$, form three walls (including top and bottom) of the test section with the fourth wall formed by the model injection system. The model is side mounted to this fourth wall. Run durations for the current tests were about one minute. Two different facility stagnation pressures, $\mathrm{P}_{0}$, were investigated: $2.41 \mathrm{MPa}(350 \mathrm{psia})$ and $8.9 \mathrm{MPa}(1300 \mathrm{psia})$. The nominal stagnation temperature was $1,005 \mathrm{~K}\left(1350^{\circ} \mathrm{F}\right)$ for the experiment described herein. The two operating pressures simulate freestream unit Reynolds numbers of 0.55 million per foot and 1.8 million per foot, respectively. Further details of the flow properties at these conditions can be found in Hollis et al. ${ }^{9}$ In addition to these tunnel-on cases, a series of runs were obtained with the wind tunnel not operating. For these tunnel-off cases, the wind tunnel test section was held at a ambient static pressure, $\mathrm{P}_{\mathrm{amb}}$, in the range of 0.025 to $0.033 \mathrm{psi}$. This pressure was chosen to approximately match the measured aft-body pressure during tunnel operation with $\mathrm{P}_{0}=1300 \mathrm{psi}$, thus providing a similar pressure ratio across the nozzle for tunnel-off and tunnel-on cases. Aft body pressures for the $\mathrm{P}_{0}=350 \mathrm{psi}$ case were too low for corresponding static-gas tests to be obtained in this facility, so were not investigated.

Nitric oxide (NO) was seeded into the RCS jet gas using two methods: first, a $5 \% \mathrm{NO}, 95 \% \mathrm{~N}_{2}$ gas bottle was used to supply gas directly for some of the test cases (less than 70 psi jet plenum pressure, $\mathrm{P}_{\mathrm{j}}$ ). The limitation on supply pressure was caused by the 100 psi pressure rating of the NO gas cabinet and supply lines, and by pressure losses in the lines. For $\mathrm{P}_{\mathrm{j}}>70 \mathrm{psi}$, a 1 liter mixing chamber was filled with $\sim 80$ psi of the $5 \% \mathrm{NO}, 95 \% \mathrm{~N}_{2}$ gas mixture and the cell was then pressurized to the desired level with pure $\mathrm{N}_{2}$. Typical $\mathrm{P}_{\mathrm{j}}$ setpoints were $56 \mathrm{psi}, 250 \mathrm{psi}$ and 500 psi, spanning the range of stagnation pressures used by Apollo Command Module $(150 \mathrm{psi})^{10}$ and currently planned for use by Orion Crew Module (200-250 psi). ${ }^{5}$ During the tunnel runs, the NO-seeded gas flowed through the model and additional $\mathrm{N}_{2}$ was supplied to the mixing chamber to maintain the desired pressure. Consequently, the concentration of NO continually dropped during the runs with an estimated decay half-life of about 15 seconds; thus, over a 60 second run, the NO concentration decreased by more than an order of magnitude. However, the NO PLIF signal intensity did not decrease proportionally because NO self-quenching diminishes as the NO concentration decreases, partially compensating for the loss of NO. The supply pressure was maintained to within $+/-20 \%$ of the desired set pressure by using a conventional single-stage, mechanical pressure regulator attached to a nitrogen bottle. The data system monitored $\mathrm{P}_{\mathrm{j}}$ using a Kulite pressure transducer. The data system logged the surface pressure using electronically scanned pressure (ESP) sensors.

As an alternative to seeding NO into the RCS jet fluid, NO was instead supplied to a forebody pressure port to allow visualization of the shear layer detached from the leeward afterbody. In this case, 100 standard cubic centimeters per minute $(\mathrm{sccm})$ of pure NO was seeded into the flow. These flowrates were lower than those required to force the forebody flow or the shear layer to transition to turbulence. For these forebody-seeded tunnel runs, pure $\mathrm{N}_{2}$ was supplied to the RCS jet and the pressure was varied.

The normal sequence of operation was to begin NO flow just as the model was injected into the wind tunnel to avoid unnecessary discharge from the mixing chamber. The data acquisition was then started and the image acquisition initiated. Consequently, $\mathrm{P}_{\mathrm{j}}$ sometimes was not stabilized during image acquisition. An output signal from the intensified CCD indicated to the data acquisition system that the PLIF image acquisition had begun. A remote manual translation stage trigger could be used to start a sweep of the laser sheet across the model for threedimensional flow visualizations.

\section{Planar Laser-Induced Fluorescence (PLIF) Imaging System}

The PLIF system consisted primarily of the laser system, beam-forming optics and the detection system. The laser system had a pump Nd:YAG laser, a tunable pulsed dye laser, and a wavelength extender, all operating at 10 Hz. The laser output was tuned to a wavelength of $226.256 \mathrm{~nm}$, chosen to excite the strongly fluorescing spectral lines of NO near the $\mathrm{Q}_{1}$ branch head. Lenses formed the laser beam into a sheet and an intensified CCD camera acquired images. Flow visualization images were acquired at $10 \mathrm{~Hz}$ with a $1 \mu$ s camera gate and a spatial resolution of about 5 pixels $/ \mathrm{mm}$ for the RCS jet imaging and 10 pixels $/ \mathrm{mm}$ for the shear layer imaging. So-called dotcards (a flat card marked with evenly spaced dots) were used to correct for image distortions and to determine image magnification in post-processing. A new method for obtaining these dotcard images was used in this experiment and is described in Inman et al. ${ }^{3}$ Further details of the PLIF system and its use in the NASA Langley Research Center 31-Inch Mach 10 Air Tunnel can be found in Refs. 1, 3 and 11. 


\section{PLIF Flow Visualization Image Processing}

Single-shot PLIF images were processed using smoothing routines and by adding false color tables. Images were corrected for spatial variations in laser sheet intensity, but neither the laser-sheet intensity nor spatial distribution was measured on a shot-to-shot basis. Rather, the average laser sheet spatial intensity variation has been measured by injecting NO into a near vacuum, resulting in uniform NO seeding, prior to the tunnel runs and acquiring an average of 100 PLIF images. Single-shot images were divided by this laser-sheet intensity profile. The images were then made into bitmap images or movies for display on the model using ViDI technology as described below. Additional details describing the image processing method for smoothing, thresholding the images, and for removal of lens and perspective distortion can be found in Ref. 6 .

\section{E. Virtual Diagnostics Interface (ViDI)}

The Virtual Diagnostics Interface (ViDI) ${ }^{12}$ is a software tool, developed at NASA Langley Research Center that provides unified data handling and interactive three-dimensional display of experimental data and computational predictions. It is a combination of custom-developed software applications and Autodesk ${ }^{\circledR} 3 \mathrm{ds} \operatorname{Max}^{\circledR}$, a commercially available, CAD-like software package for three-dimensional rendering and animation. ${ }^{13}$ ViDI technology can be applied to three main areas: 1) pre-test planning and optimization; 2) visualization and analysis of experimental data and/or computational predictions; and 3) establishment of a central hub to visualize, store and retrieve experimental results. For this experiment, ViDI was used primarily for post-test visualization of the PLIF data as in Ref. 6.

\section{Results}

\section{A. Comparison between Tunnel-off and Tunnel-on Images}

Figure 2 shows a comparison between two images obtained using the cone nozzle: one with the wind tunnel not operating (tunnel-off) and the other with the wind tunnel operating (tunnel-on). For the tunnel-off case, the wind tunnel test section was held at a static pressure in the range of $0.025 \pm 0.001 \mathrm{psi}$. A few comments on the color tables are required to correctly interpret the images. First, the images are shown in false color. While the CCD camera captures fluorescence in monochrome, the images are processed with false color to enhance the flow features. Secondly, brightness in the image roughly correlates to higher NO concentration. So, bright regions have high NO density (and high gas density) while very low signals indicate either regions having no seeded NO, for example far from the jet, or regions of very low gas density within the jet. For the case of the tunnel-off flow, Fig. 2(a) exhibits a classic underexpanded jet structure ${ }^{14}$ with an axisymmetric barrel shock and a Mach disk at the top right of the image (barely visible in this single-shot image). The flow is observed to be transitioning to turbulent far from the nozzle exit, along both top and bottom shear layers just outside the barrel shock.

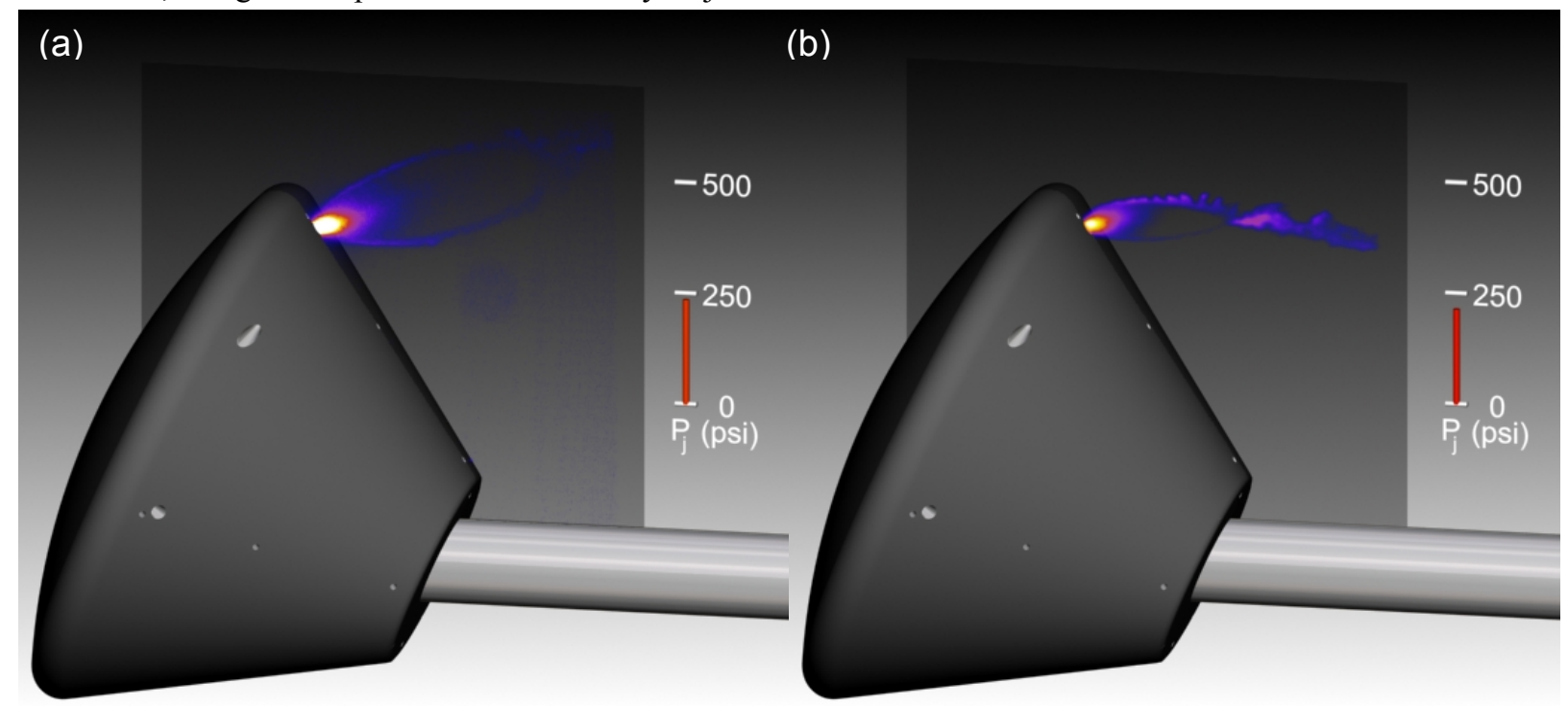

Figure 2: NO PLIF visualizations of $P_{j}=250$ psi RCS jet flows issuing from the cone nozzle for the tunnel-off, $P_{a m b}=0.025$ psi case (a) and the tunnel-on, $\mathrm{P}_{0}=1,300$ psi case (b). 
An image from the corresponding tunnel-on run is shown in Fig. 2(b), which shows a smaller and more asymmetric jet with a transitioning shear layer on the top of the RCS jet. The shear layer on the bottom of the jet is more laminar and steady than the top, though many of the images obtained during this run showed turbulent structures on the bottom of the jet as well. Comparison of the two images reveals that the bottom side of the two RCS jets are fairly similar in shape and location while the top side of the tunnel-on case is truncated or compressed compared to the tunnel-off case. This is because the RCS jet is penetrating into rapidly-moving gas that has expanded around the shoulder of the forebody. Clearly, the Mach 10 gas flow significantly modifies the RCS jet flow. Below, it is shown that the RCS jet flow also modifies the gas flow over the capsule as well. The collision between the RCS jet and the flow emanating from the forebody is studied in more detail later in this paper where experiments are described in which $\mathrm{NO}$ is added to the forebody flow.

\section{B. Comparison of Flow from Cone- and Bell-Shaped Nozzles}

Figure 3 shows a comparison between RCS jet flow for the two nozzle geometries. Both images show results for the same RCS jet pressure, $\mathrm{P}_{\mathrm{j}}$, issuing into low-pressure static gas in the wind tunnel test section. The left image shows data from the cone nozzle while the right image shows data from the bell nozzle. As mentioned above, the cone nozzle flow produces a highly underexpanded axisymmetric jet. The flow between the barrel shocks near the nozzle is relatively smooth and uniform, acting as if originating from a collimated flow. The image from the bell nozzle shows a similar barrel shock structure. Differences in the size of the barrel shock structure may have been caused by slightly different pressure ratios across the nozzle, owing to the slightly different ambient pressure in the two tests. However, in Fig. 3(b), if the nozzle flow inside the barrel shocks is studied, at least three peaks are observed originating at the nozzle exit. These multi-peaked structures are laminar, steady, and are present in nearly every image. Sweeping the laser sheet through the flow shows that the pattern is axisymmetric in this case as well. Thus, there is a conical flow pattern originating at the nozzle exit which surrounds a central spike. Considering that the internal structure of the jet is so different in the two cases, it is surprising that the flow on the edges of the jet plume is so similar. The two nozzles have different Mach numbers (4.3 vs 4.9) so one might expect a more radically different outer jet shape.

Two different causes have been suggested for these flow structures observed in the case of the bell nozzle. The first possible cause of these structures is shock focusing caused by the transition from contoured to conical nozzle shapes in the bell nozzle. Compression and expansion waves in the nozzle could produce focusing effects on the center line as well as conical shaped disturbances. If this is true, then it represents an undesirable loss mechanism. An ideal jet would flow isentropically through the nozzle, whereas shockwaves in the nozzle would increase the entropy thereby reducing the efficiency of the nozzle. Computational fluid dynamics analysis of these two nozzle shapes will either confirm or deny this hypothesis.

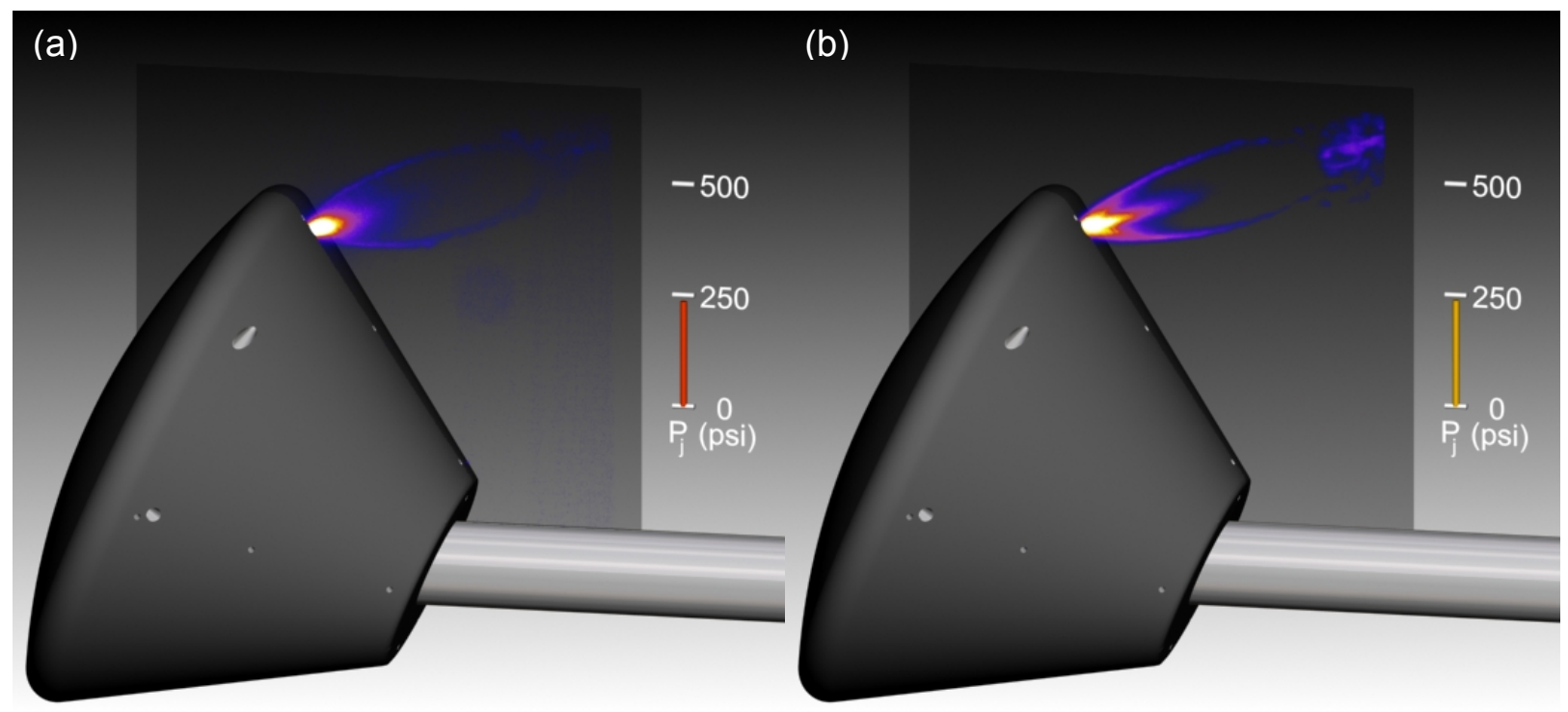

Figure 3 NO PLIF visualizations RCS jet flows for $P_{j}=250$ issuing into a low-pressure static gas. The left image (a) shows the cone nozzle issuing into $\mathrm{P}_{\mathrm{amb}}=0.025 \pm 0.001 \mathrm{psi}$ while the right image (b) shows the bell nozzle, issuing into $\mathrm{P}_{\mathrm{amb}}=$ $0.030 \pm 0.001 \mathrm{psi}$. The color of the pressure bar scale has no significance in this figure. 


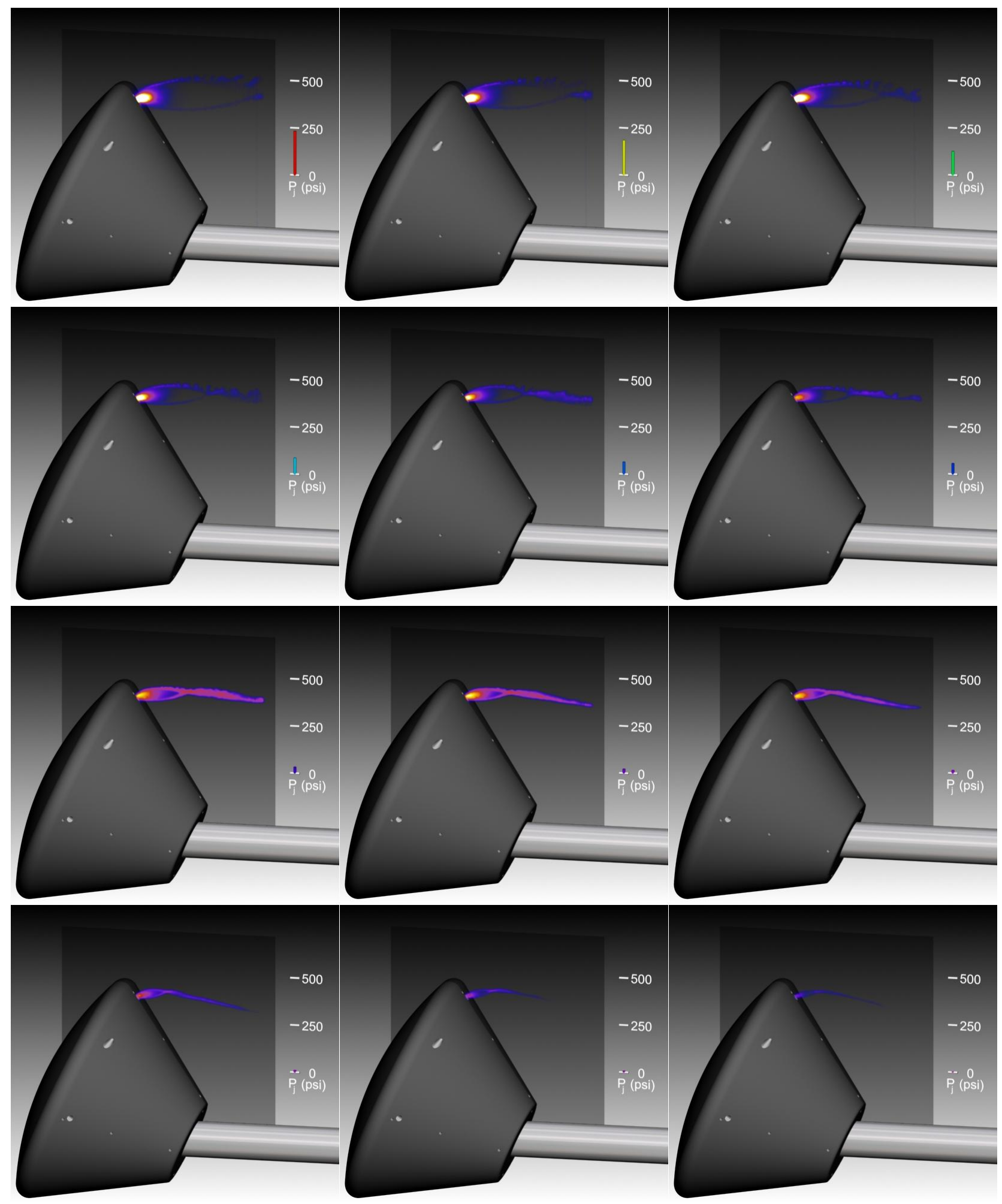

Figure 4: NO PLIF visualizations of RCS jet flows at $\mathrm{P}_{0}=350$ psi for the cone nozzle. The jet pressure varies, as indicted by the bar graph in each image.

A second possible cause of these structures is condensation of the nitrogen gas flowing through the nozzle. The gas is supplied to the model at room temperature. After flowing from $\mathrm{P}_{\mathrm{j}}=500$ psi through a Mach 4.3 nozzle, the 
gas temperature and pressure at the exit of the nozzle is predicted to be $65 \mathrm{~K}\left(117^{\circ}\right.$ Rankine) and $16.3 \mathrm{kPa}(2.36 \mathrm{psi})$ respectively, according to perfect gas calculations, assuming a constant ratio of specific heats equal to 1.4. Coincidentally, this temperature is within one Kelvin of the condensation temperature (boiling point) of $\mathrm{N}_{2}$ at 16.3 $\mathrm{kPa}^{15}$ Jet pressures below $500 \mathrm{psi}$ do not reach the condensation temperature while inside the nozzle. By contrast, the nitrogen gas exiting the bell nozzle with a Mach number is 4.9 is predicted to be much colder: $52 \mathrm{~K}\left(94^{\circ}\right.$ Rankine) as well as lower pressure: $7.6 \mathrm{kPa}(1.1 \mathrm{psi})$. This temperature is well below the $60 \mathrm{~K}$ (108 Rankine) required to condense $\mathrm{N}_{2}$ at this nozzle exit pressure. ${ }^{15}$ The condensation process probably requires many collisions to occur, and the transit time through the nozzle is fast. Nonetheless, these calculations show a strong possibility of condensation in the bell nozzle.

Data from all of the pitch RCS jet runs are shown in the appendix. In all the figures of the appendix the left column shows images acquired with the bell nozzle and the right column shows images acquired with the cone nozzle. The figures allow for further comparisons to be made between the two nozzle geometries over the full range of flow conditions tested in the experiment. These figures show that at sufficiently low jet pressure, the bell and the cone nozzles are very similarly shaped internal to the jet plume. That is, the bell nozzle does not show the central spike surrounded by the conical flow structure for lower pressure operation. Transition between these types of nearfield flow structures occurs between $P_{j}=80$ and 200 psi. A sudden transition in flow structures is consistent with condensation; as $P_{j}$ decreases, the drop in the exit pressure lowers the condensation temperature to a value lower than the exit temperature of the nozzle and the condensation would therefore not occur.

More sophisticated calculations for this flow should be performed to determine if condensation is occurring. The 500 psi jet pressure used in this experiment exceeds the pressure at the critical point of $\mathrm{N}_{2}$, so simple perfect-gas computations such as those used in this discussion are not completely valid. Additionally, the condensation process may require finite-rate chemical modeling. Nonetheless, this discussion has shown that condensation is possible at these conditions and is more likely for the bell nozzle than the cone nozzle.

Even if CFD solutions indicate that the shape of the nozzle is responsible for these unexpected flow features, the possibility of condensation modifying the RCS jet flow still exists and should be further investigated. Of course, in real RCS jet firings on the actual flight vehicles, chemical reactions heat the gas in the plenum of the nozzle, thereby increasing the nozzle exit temperature, so condensation is less likely to occur. Nonetheless, it is important to provide well-understood ground-based simulations of these flows for code validation. Consequently, in future experiments, the Mach number of tested RCS nozzles should be held to less than 4.3 for $\mathrm{P}_{\mathrm{j}}=500$ psi operation. Operation at higher pressures would require even lower Mach number nozzles to avoid condensation.

\section{Influence of Jet Pressure, $P_{j}$ on Jet Structure}

Figure 4 shows a series of images acquired towards the end of one tunnel run using the cone nozzle. The jet pressure was continuously decreased from a maximum of $250 \mathrm{psi}$ to 0 . As $\mathrm{P}_{\mathrm{j}}$ decreased, it was observed that the barrel shock shrank. The intersection between the capsule shear layer atop the barrel shock and the bottom of the barrel shock moved closer to the nozzle exit. When the pressure fell below approximately 75 psi, the jet filled in, showing fluorescence signal throughout the center of the jet inside the barrel shock. At the lower flow rates, transitional and/or turbulent structures on the edge of the jet became smaller and less dynamic. At sufficiently low jet pressure, the jet became laminar as shown in the bottom row of the figure. In the last figure, the barrel shock pattern was still, albeit barely, visible. One conclusion from this test was that the jet pressure had a much more significant effect on the jet plume exterior shape and size than the shape of the nozzle itself.

\section{Variation of Jet Structure with Reynolds Number}

Tests were performed to have low- and high-tunnel-stagnation pressure conditions to determine the effects of viscosity associated with a factor of 4 change in Reynolds number. Figure 5 compares images obtained on low $\left(0.55 \times 10^{6} /\right.$ foot $)$ and high $\left(1.8 \times 10^{6} /\right.$ foot $)$ Reynolds number runs using the same jet pressure. The most obvious difference between the two images is the size (both width and length) of the barrel shock. The high-Reynolds number case had a much smaller barrel shock because the pressure ratio across the nozzle, which determines the size of the barrel shock, was much smaller than in the low Reynolds number case. The jet did not deflect the shear layer as far in the high Reynolds number case. Both images show transitional or turbulent flow structures on the top of the barrel shock. In the high-Reynolds number case, more fully developed turbulence was observed further downstream. 


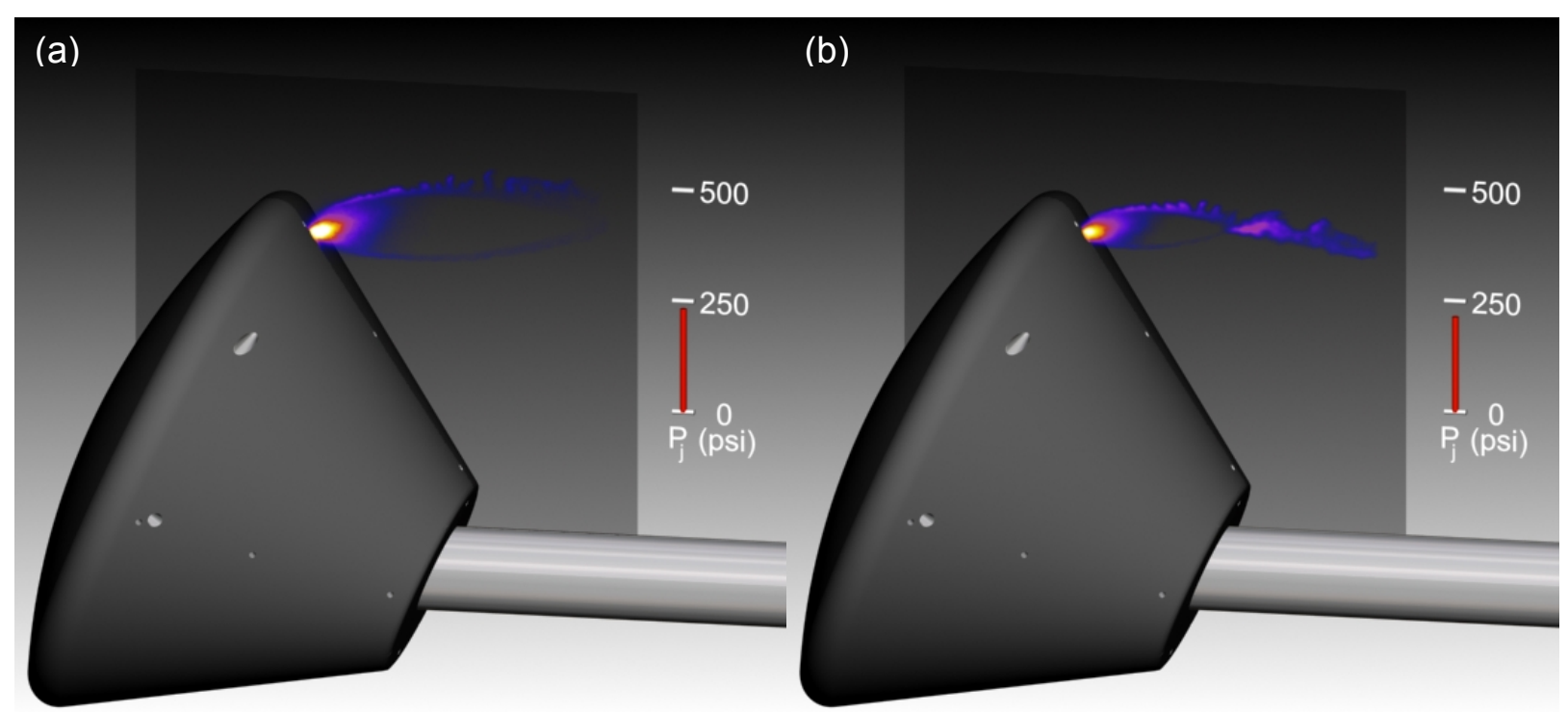

Figure 5: NO PLIF visualizations of RCS jet flows with the cone nozzle for two different freestream Reynolds numbers and similar jet pressures: (a) $\mathrm{P}_{0}=350$ psi and (b) $\mathrm{P}_{0}=1300$ psi. For both runs, the jet pressure was set to a nominal value of 250 psi.

If Reynolds number effects are to be isolated and compared, the jet pressure should be scaled proportionally with the tunnel stagnation pressure so that the size of the barrel shock is the same in both cases. Then, only Reynolds number effects would be observed. The ratio $\mathrm{P}_{0} / \mathrm{P}_{\mathrm{j}}$ equals 6.0 for the image shown in Fig. 5(b). Coincidentally, another tunnel run at the lower Reynolds number condition also had a ratio of $\mathrm{P}_{0} / \mathrm{P}_{\mathrm{j}}=6.0$. Figure 6 compares images taken during these two runs. As expected, the size and shape of the barrel shocks is very similar in the two images. The right-hand side of Fig. 6(a) shows larger, more coherent structures compared to Fig. 6(b), which shows smallerscale, more turbulent structures, particularly on the far right side of both images.

Another significant difference between the images is the fluorescence intensity inside the barrel shock. In the low-stagnation-pressure case, fluorescence signal is observed throughout the gas bounded by the barrel shock. In the high-stagnation-pressure case, the fluorescence intensity is very bright at the nozzle exit but diminishes rapidly and, on this color table, goes away completely inside the barrel shock structure. The fluorescence intensity depends in a complicated way on the gas composition and also the gas temperature and pressure, both of which are changing

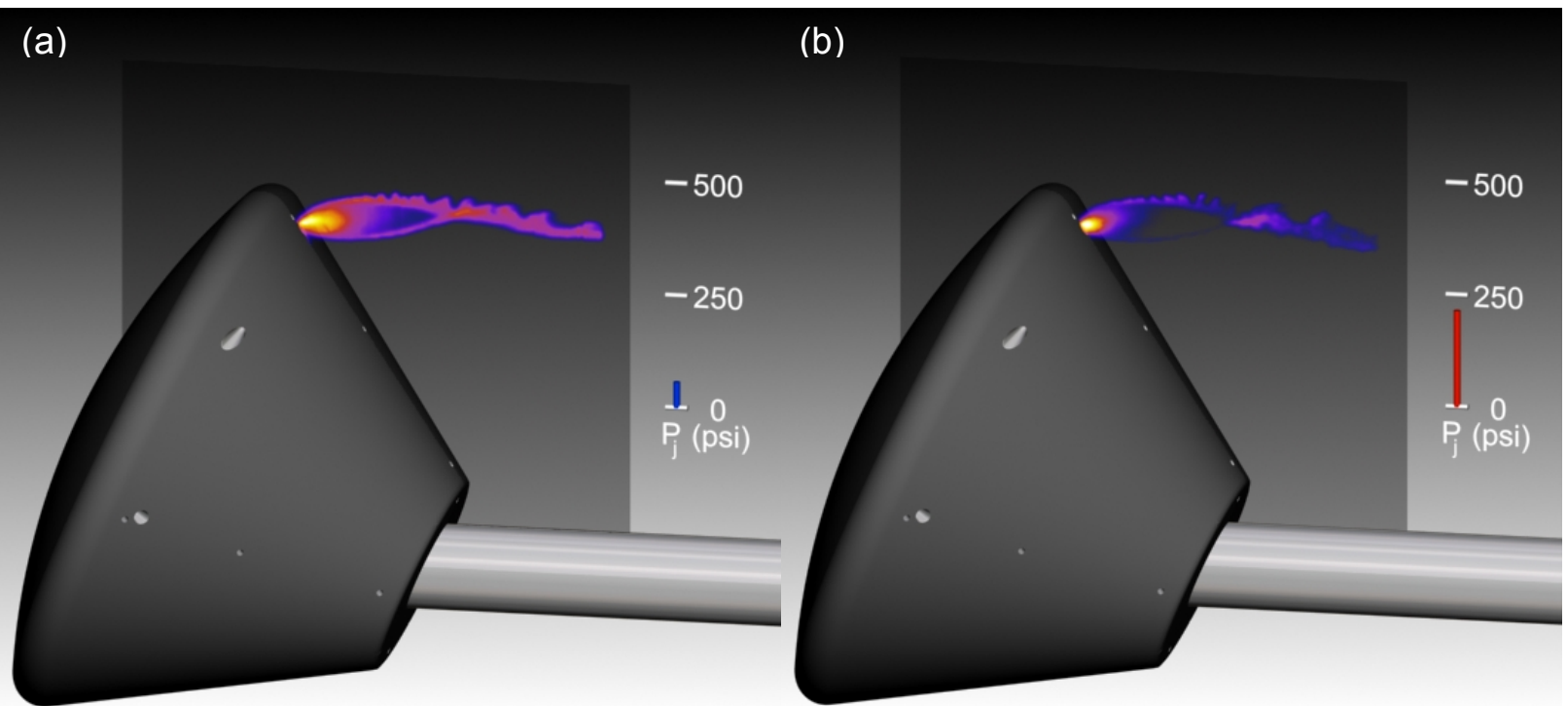

Figure 6: NO PLIF visualizations of RCS jet flows with the cone nozzle for two different freestream Reynolds numbers, while keeping the ratio of $\mathrm{P}_{0} / \mathrm{P}_{\mathrm{j}}=$ constant: (a) $\mathrm{P}_{0}=350$ psi and $\mathrm{P}_{\mathrm{j}}=58$ psi and (b) $\mathrm{P}_{0}=1300$ psi and $\mathrm{P}_{\mathrm{j}}=215$ psi. 
dramatically as the gas passes from the nozzle through the inside of the barrel shock structure. The difference in composition in these jets (5\% NO in Fig. 6(a) vs. $\sim 1 \% \mathrm{NO}$ in Fig. 6(b)) is probably largely responsible for the difference in appearance. Self quenching of NO limits the fluorescence intensity near the nozzle exit when the NO concentration is high, probably resulting in the more uniform appearance within the barrel shock of Fig. 6(a). These trends in the fluorescence intensity can be predicted using detailed spectral modeling. ${ }^{16}$ In the future, we plan to use computational predictions of the flow along with the detailed spectral model to interpret differences that arise in fluorescence images and also to allow direct comparison between PLIF images and CFD. ${ }^{14,17}$

\section{E. Influence of Jet Pressure, $P_{\mathbf{j}}$ on Leeward Aftbody Shear Layer}

Seeding pure nitric oxide from the topmost pressure port of the model forebody visualized the shear layer that formed between the gas passing over the model and the recirculating separated flow in the wake of, and adjacent to, the model. If a sufficiently low flow rate $(<200 \mathrm{sccm})$ of $\mathrm{NO}$ was used, then this shear layer flow remained laminar. For the images shown in Fig. 7, a constant $100 \mathrm{sccm}$ flow rate of pure NO was used and the jet pressure was varied. Pure $\mathrm{N}_{2}$ gas was used in the jet. For both the tunnel stagnation pressure conditions, the images show a laminar flow when the jet pressure is zero. The shear layers are observed to be straight, though observation of a series of such images shows that the shear layer flaps from shot to shot and is sometimes slightly curved. As the jet pressure increases, the shear layer deflects out away from the body, deflected by the jet plume. Also the shear layer and jet gas mix. At sufficiently low jet pressures, the deflected shear layer remains laminar, but above a critical value of jet pressure, it transitions to turbulence. For example, for $\mathrm{P}_{\mathrm{j}}>12 \pm 1 \mathrm{psi}$, the shear layer is transitional or turbulent for the $\mathrm{P}_{0}=1300$ psi case. The higher the jet pressure, the further the shear layer is deflected. The flow structures visualized appear to be organized and correlated in shape and size with adjacent structures in the shear layer. However, the structures in subsequent images, acquired 0.1 seconds apart, show different shapes.

Operation of the RCS jet moves the flow separation points of the shear layer as it passes around the leeward shoulder of the model. Figure 7 shows that, when the RCS jet is flowing, the incipient flow separation is further aft (and much closer to the nozzle exit) than in the no-flow cases. The presence of the jet forces the shear layer to stay attached to the surface above and to the left of the jet in the images.

Comparing the low Reynolds number (low $\mathrm{P}_{0}$ ) to high Reynolds number (high $\mathrm{P}_{0}$ ) cases shows that the seeded flow stream is thicker in the lower Reynolds number case - this was observed in all the images, not just the two shown here. Also, for the same jet pressure, the deflection of the shear layer is less in the low $\mathrm{P}_{0}$ case than in the high $\mathrm{P}_{0}$ case. Probably this is caused by a higher ratio of $\mathrm{P}_{\mathrm{j}} / \mathrm{P}_{0}$ in the lower $\mathrm{P}_{0}$ case which results in a larger pressure ratio across the nozzle and a larger barrel shock structure. The higher Reynolds number case shows slightly more random and smaller turbulent structures than the lower Reynolds number case, as expected. But even in the higher Reynolds number case, many organized transitional flow structures are present - fully turbulent flow is seldom observed in the data from these two runs. Note that a camera had a much smaller field of view in these shear layer visualization runs compared to the RCS jet visualization runs. In the RCS jet visualizations, the turbulent structures were more likely to be found further downstream than the field of view of the camera used to acquire the images shown in Fig. 7.

\section{Conclusion}

The nitric oxide PLIF technique has been used to visualize RCS jets for a range of jet pressures and tunnel stagnation pressure conditions. Additionally, PLIF was used to visualize the interaction of the shear layer between the gas flowing around the model and the separated gas flow behind the model with the RCS jet. PLIF identified unexpected disturbances in one of the nozzles tested: the bell nozzle. These disturbances could either be caused by shock focusing or condensation. Most of the testing in this experiment used the bell nozzle. ${ }^{5}$ This nozzle provided an unrealistic simulation of flight-vehicle RCS jets, which have smoothly varying contours and operate at much higher temperatures, avoiding condensation. These disturbances probably would not have been noticed if PLIF had not been used in this test. PLIF also identified the trajectory and penetration of the RCS jets under a variety of flow conditions. It is anticipated that these data will be compared with computational simulations of this experiment. Using computed results along with a spectral model for the fluorescence process, theoretical PLIF mages can be calculated and compared directly to experimental images. Such comparisons will help validate the computations. In the future, quantitative measurements such as flowfield velocity, to be obtained using PLIF, will provide additional code validation data. 

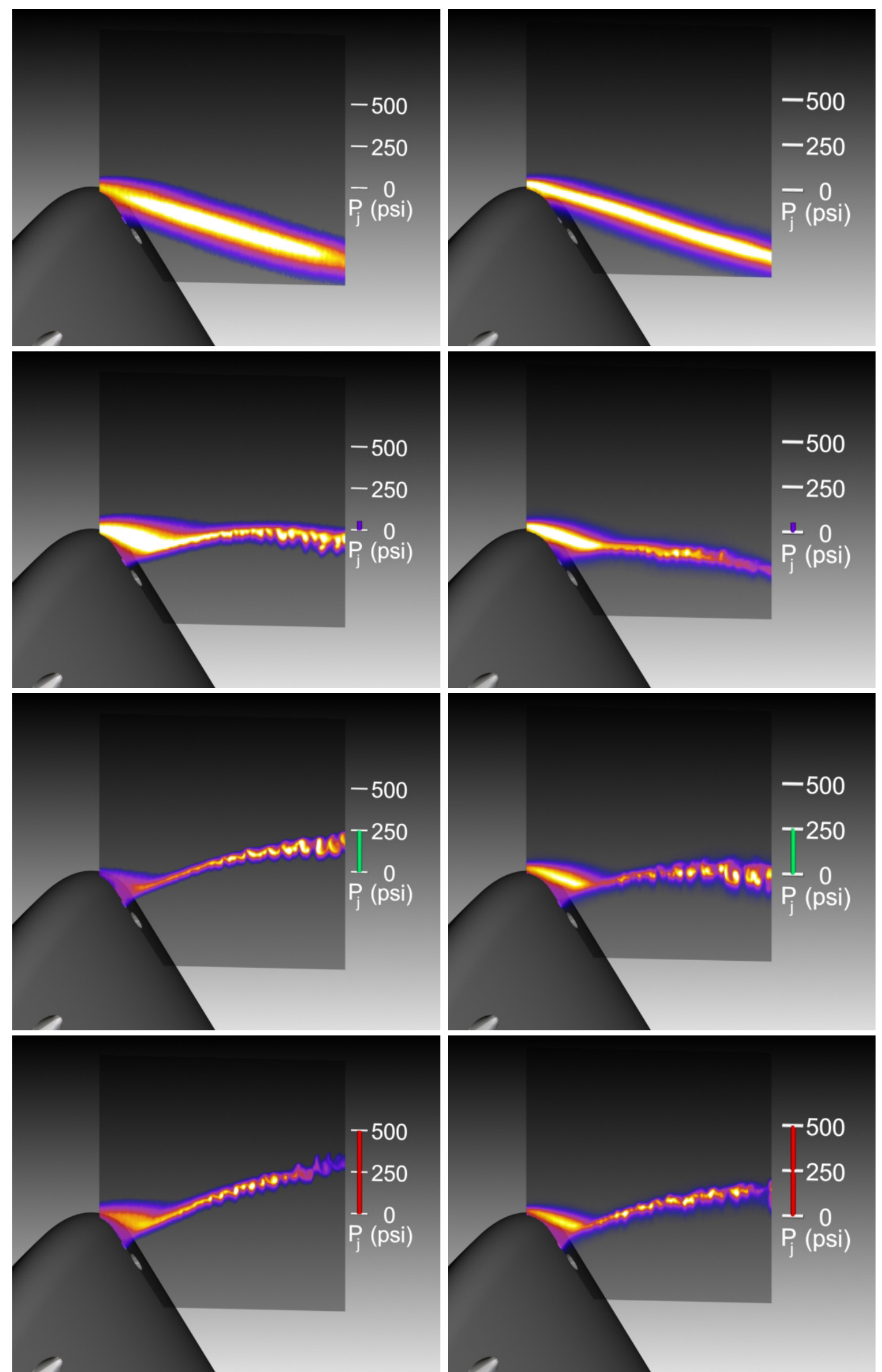

Figure 7: NO PLIF visualization of the capsule's leeward aft body shear layer. The images in the left column were obtained with tunnel stagnation pressure, $\mathrm{P}_{0}=350$ psi while the right column had $\mathrm{P}_{0}=1,300 \mathrm{psi}$. The jet pressure was varied as indicated by the bar graph in each image. 


\section{Acknowledgments}

We wish to acknowledge the contribution to this project from the NASA Langley Research Center 31-Inch Mach 10 Air Tunnel technicians and engineers, including Kevin Hollingsworth, Paul Tucker, Tony Robbins, Henry Fitzgerald and Johnny Ellis. This work was supported by the NASA Fundamental Aeronautics Hypersonics Program as well as NASA's Constellation Orion CEV Aeroscience Program (CAP). Thanks also to Rich Schwartz and Andrew McCrea from ATK, Hampton Virginia, for assisting with the computer visualizations of the data.

\section{References}

${ }^{1}$ P. M. Danehy, J. A. Wilkes, G. Brauckmann, D. W. Alderfer, S. B. Jones, and D. Patry, "Visualization of a Capsule Entry Vehicle Reaction-Control System (RCS) Thruster," AIAA Paper 2006-1532, 44 ${ }^{\text {th }}$ AIAA Aerospace Sciences Meeting and Exhibit, Reno, Nevada, Jan. 9-12, 2006.

${ }^{2}$ E. Cecil and J. C. McDaniel, "Planar Velocity and Temperature Measurements in Rarefied Hypersonic Flow Using Iodine LIF," 38th AIAA Thermophysics Conference, 6 - 9 June 2005, Toronto, Ontario Canada, AIAA 2005-4695.

${ }^{3}$ J. A.(Wilkes) Inman, P. M. Danehy, D. W. Alderfer, and G. M. Buck, A. McCrea, and R. J. Schwartz, "PLIF Imaging of Capsule RCS Jets, Shear Layers, and Simulated Forebody Ablation," AIAA Paper 2008-0248, $46^{\text {th }}$ AIAA Aerospace Sciences Meeting and Exhibit, Reno, Nevada, Jan. 7-10, 2008.

${ }^{4}$ A. N. Watkins, G. M. Buck, B. D. Leighty, and W. E. Lipford, "Using Pressure- and Temperature-Sensitive Paint for Global Surface Pressure and Temperature Measurements on the Aft-Body of a Capsule Reentry Vehicle," AIAA Paper 20081230, $46^{\text {th }}$ AIAA Aerospace Sciences Meeting and Exhibit, Reno, Nevada, Jan. 7-10, 2008

${ }^{5}$ G. M. Buck, A. N. Watkins, P. M. Danehy, J. A. Inman, D. W. Alderfer, A. A. Dyakonov, "Experimental Measurement of RCS Jet Interaction Effects on a Capsule Entry Vehicle," AIAA Paper 2008-1229, $46^{\text {th }}$ AIAA Aerospace Sciences Meeting and Exhibit, Reno, Nevada, Jan. 7-10, 2008.

${ }^{6}$ D.W. Alderfer, P.M. Danehy, J.A. Wilkes Inman, K.T. Berger, G.M. Buck, and R. J. Schwartz, "Fluorescence Visualization of Hypersonic Flow Over Rapid Prototype Wind-Tunnel Models" AIAA Paper 2007-1063, 45th AIAA Aerospace Sciences Meeting and Exhibit, Reno, Nevada, Jan. 8-11 (2007).

${ }^{7}$ R. Mitcheltree, A. Steltzner, A. Chen, M. San Martin, T. Rivellini, "Mars science laboratory entry descent and landing system verification and validation program," IEEE Aerospace Conference, Big Sky, MT, March 04-11, 2006.

${ }^{8}$ J. R. Micol "Langley Aerothermodynamic Facilities Complex: Enhancements and Testing Capabilities," AIAA Paper 980147, 36th AIAA Aerospace Sciences Meeting \& Exhibit, January 12-15, Reno, NV, 1998

${ }^{9}$ Hollis, B.R. "Real-gas flow properties for NASA Langley Research Center Aerothermodynamics Facilities Complex Wind Tunnels,” NASA Contractor Report 4755, Sept. 1996.

${ }^{10}$ C. A. Vaughan, “Apollo Reaction Control Systems," AIAA Paper Number 68-566 (1968)

${ }^{11}$ J. A. Wilkes, D. W. Alderfer, S. B. Jones, and P. M. Danehy, "Portable Fluorescence Imaging System for Hypersonic Flow Facilities," JANNAF Interagency Propulsion Committee Meeting, Colorado Springs, Colorado, December 2003.

${ }^{12}$ R. J. Schwartz, "ViDI: Virtual Diagnostics Interface Volume 1-The Future of Wind Tunnel Testing" Contractor Report NASA/CR-2003-212667, December 2003.

${ }^{13}$ Autodesk 3ds Max Product Information, Autodesk Inc., http://usa.autodesk.com/adsk/servlet/index?id=5659302\&siteID=123112, viewed Jan 2, 2006.

${ }^{14}$ J. A. Wilkes, C. Glass, P. M. Danehy and R. J. Nowak, "Fluorescence Imaging of Underexpanded Jets and Comparison with CFD” AIAA Paper 2006-910 44th AIAA Aerospace Sciences Meeting and Exhibit, Reno, Nevada, Jan. 9-12, 2006.

${ }^{15}$ Air Liquide Gas Encyclopaedia,

http://encyclopedia.airliquide.com/images_encyclopedie/VaporPressureGraph/Nitrogen_Vapor_Pressure.GIF, cited December 10, 2007.

${ }^{16}$ Paul, P. H., Gray, J. A., Durant, J. L., Jr., and Thoman, J. W., Jr., "Collisional Quenching Corrections for Laser-Induced Fluorescence Measurements of NO A² $\Sigma^{+}$," AIAA Journal, Vol. 32, No. 8, 1994, pp. 1670-1675.

${ }^{17}$ P. M. Danehy, P. C. Palma, R. R. Boyce, A. F. P. Houwing, "Numerical simulation of laser-induced fluorescence imaging in shock-layer flows", AIAA Journal, Vol. 37 p. 715-722 (1999). 


\section{Appendix: Summary of PLIF Images of Pitch RCS Jets}

The six figures on the following pages, each containing six images, are organized according to Table A1. The organization of the images is duplicated in all six figures to facilitate page-to-page comparisons of the jet shapes. Pressures indicated in this table are nominal. Actual pressures are indicated by the bar graphs in the images. Table A2 indicates the average ambient static pressures the RCS jets flow into for Figures A1 and A2. For Figures A3-A6 the caption at the bottom of each figure indicates the tunnel stagnation pressure. In summary, Figures A1-A6 within this appendix show:

Figure A1: Single-shot images of RCS jet flows into static low pressure gas

Figure A2: Averaged images of RCS jet flows into static low pressure gas

Figure A3: Single-shot images of RCS jet flows with tunnel operating at $P_{o}=350$ psi.

Figure A4: Averaged images of RCS jet flows with tunnel operating at $P_{o}=350$ psi.

Figure A5: Single-shot images of RCS jet flows with tunnel operating at $P_{o}=1300$ psi.

Figure A6: Averaged images of RCS jet flows with tunnel operating at $P_{o}=1300$ psi.

\begin{tabular}{|c|c|}
\hline Bell nozzle & Cone nozzle \\
$\mathrm{P}_{\mathrm{j}}=56 \mathrm{psi}$ & $\mathrm{P}_{\mathrm{j}}=56 \mathrm{psi}$ \\
\hline & \\
\hline Bell nozzle & Cone nozzle \\
$\mathrm{P}_{\mathrm{j}}=250 \mathrm{psi}$ & $\mathrm{P}_{\mathrm{j}}=250 \mathrm{psi}$ \\
\hline & \\
\hline Bell nozzle & Cone nozzle \\
$\mathrm{P}_{\mathrm{j}}=500 \mathrm{psi}$ & $\mathrm{P}_{\mathrm{j}}=500 \mathrm{psi}$ \\
\hline
\end{tabular}

Table A1. Layout of all figures shown in this appendix.

Pressures shown are nominal.

\begin{tabular}{|l|l|}
\hline $\mathrm{P}_{\mathrm{a}}=0.032 \mathrm{psi}$ & $\mathrm{P}_{\mathrm{a}}=0.024 \mathrm{psi}$ \\
\hline $\mathrm{P}_{\mathrm{a}}=0.032 \mathrm{psi}$ & $\mathrm{P}_{\mathrm{a}}=0.025 \mathrm{psi}$ \\
\hline $\mathrm{P}_{\mathrm{a}}=0.035 \mathrm{psi}$ & $\mathrm{P}_{\mathrm{a}}=0.027 \mathrm{psi}$ \\
\hline
\end{tabular}

Table A2. Static gas pressures corresponding to the six images in Figures A1 and A2. 

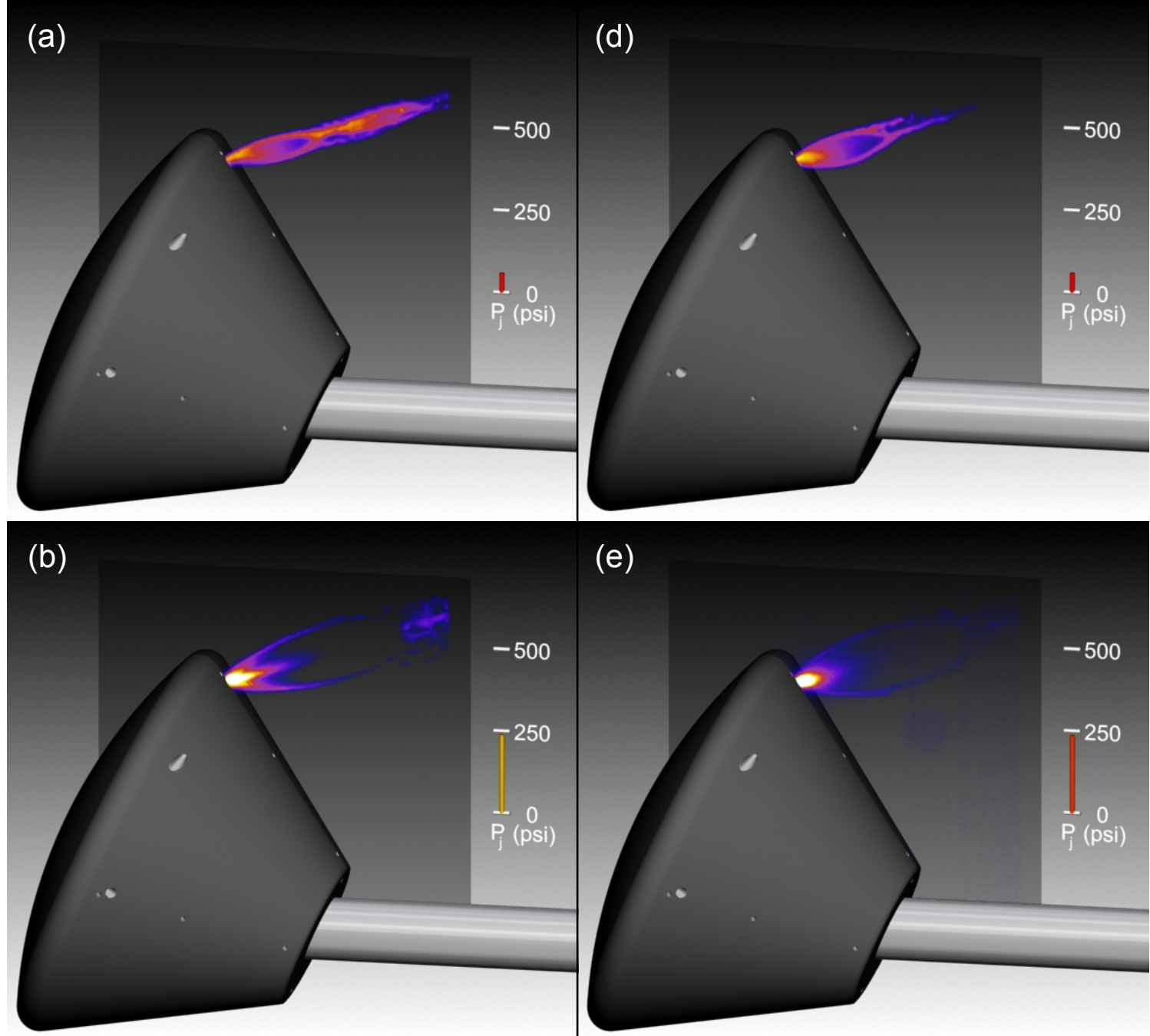

(e)

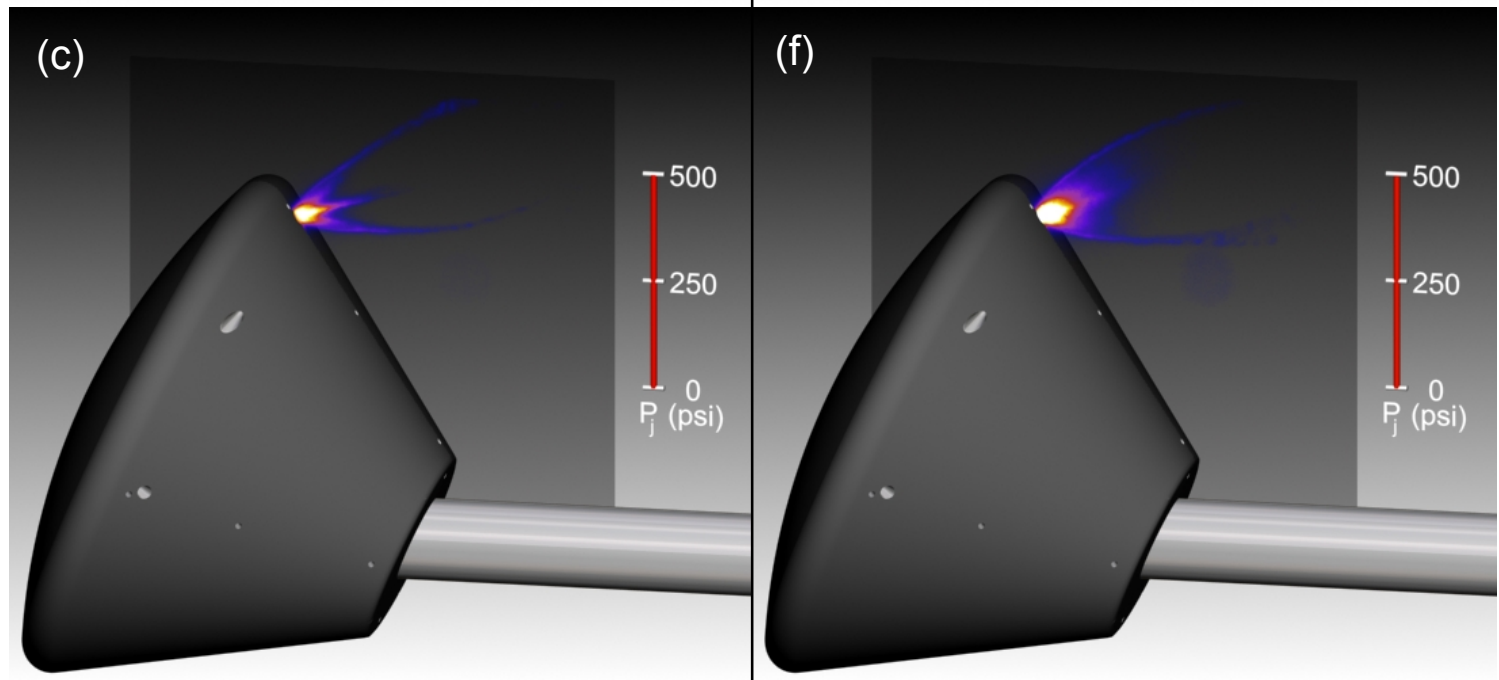

Figure A1: NO PLIF visualizations of RCS jet flows for flow into static gas: single-shot images. The left column is for the bell nozzle while the right column is for the cone nozzle. The jet pressures are indicated by the bar graph. The color of the bar in the graph is insignificant. 

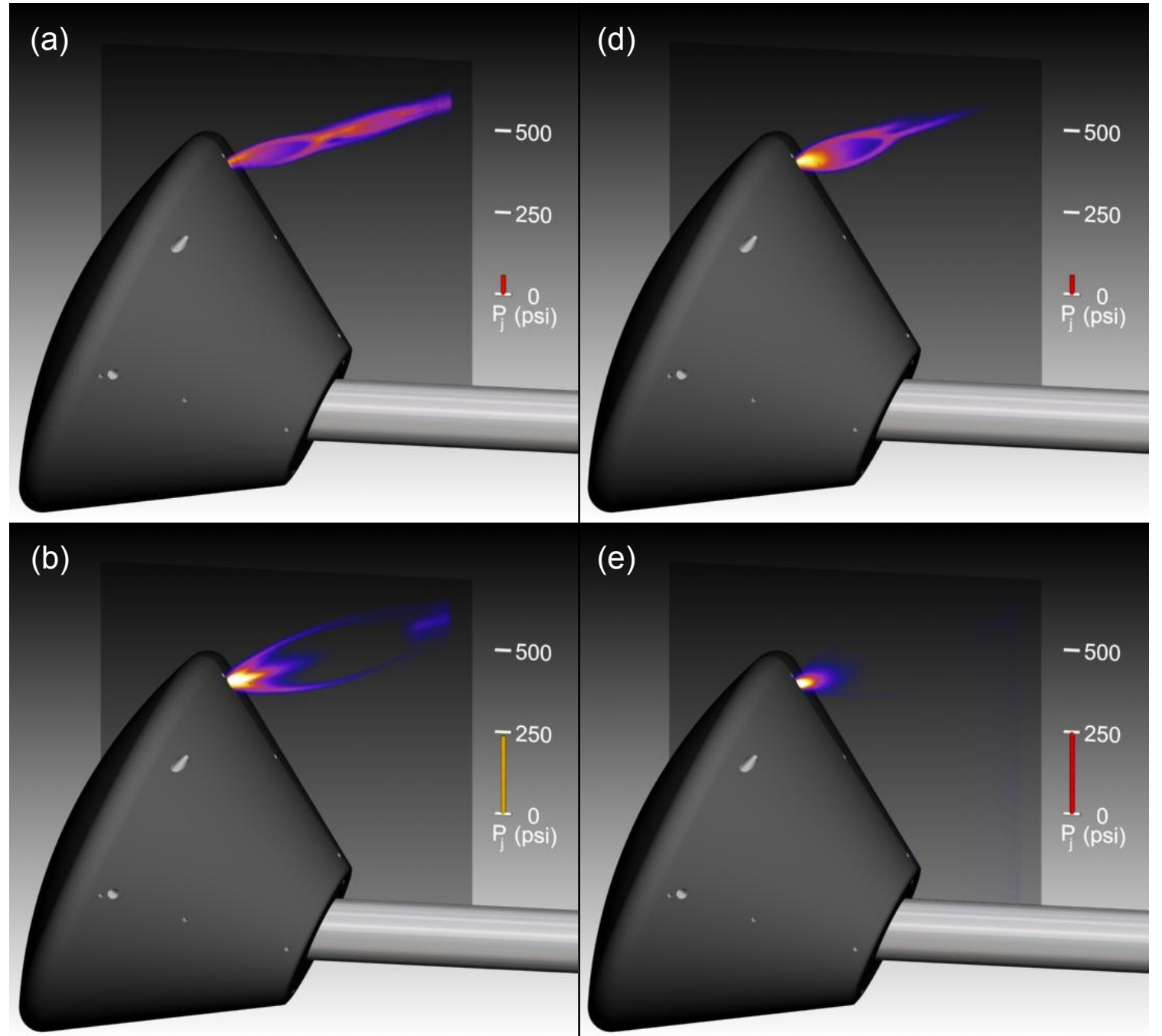

(e)

)

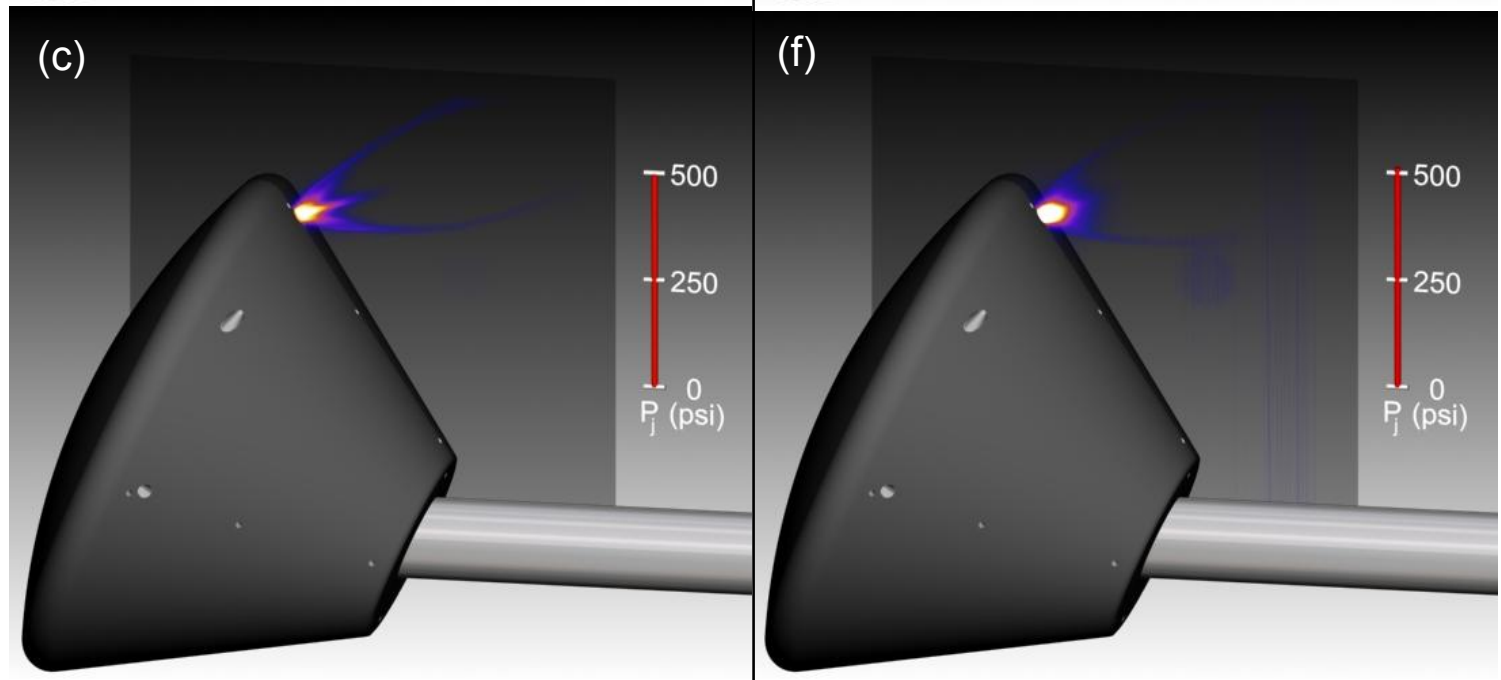

Figure A2: NO PLIF visualizations of RCS jet flows for flow into static gas: averaged images. The left column is for the bell nozzle while the right column is for the cone nozzle. The jet pressures are indicated by the bar graph. The color of the bar in the graph is insignificant. 

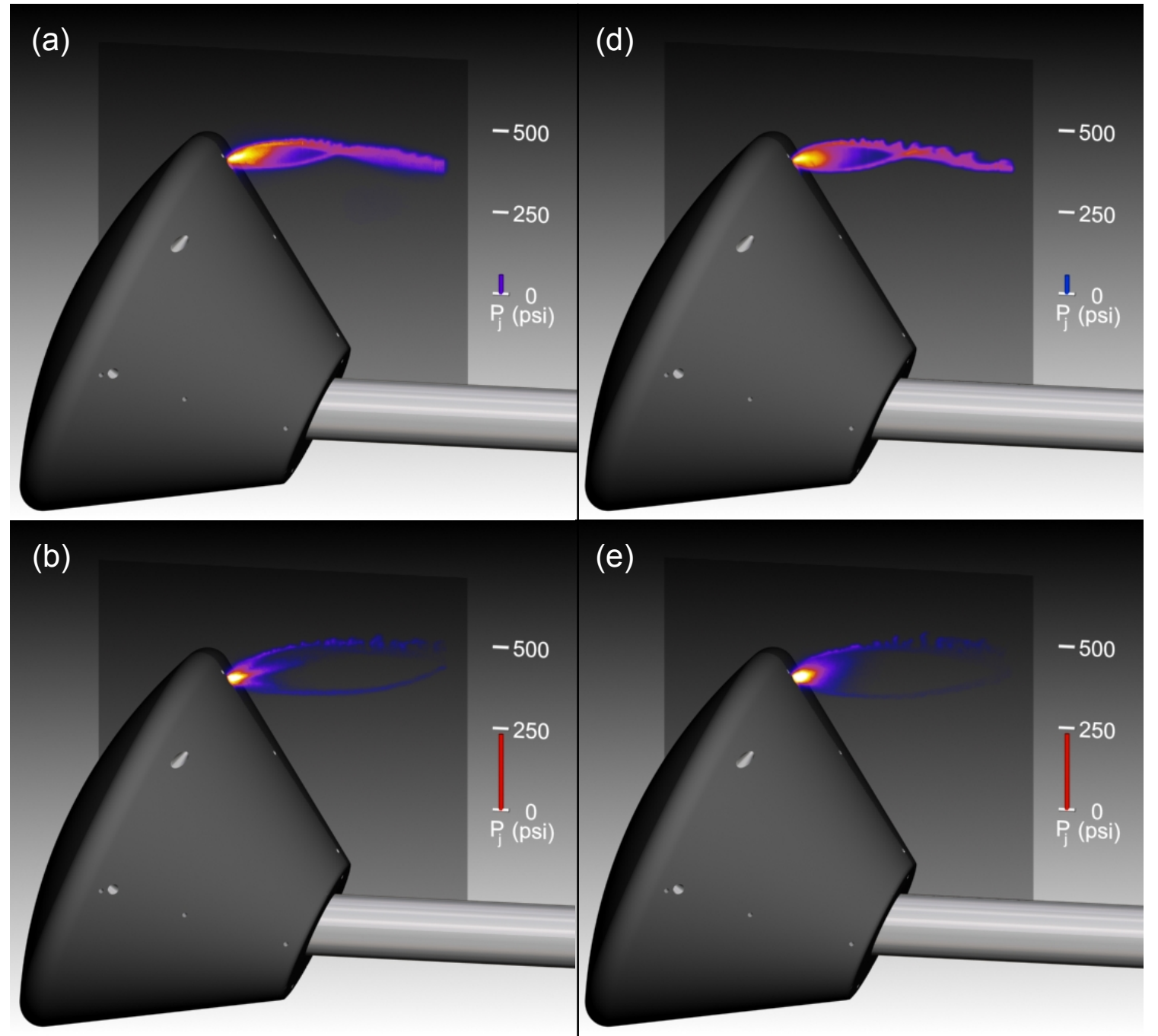

(e)
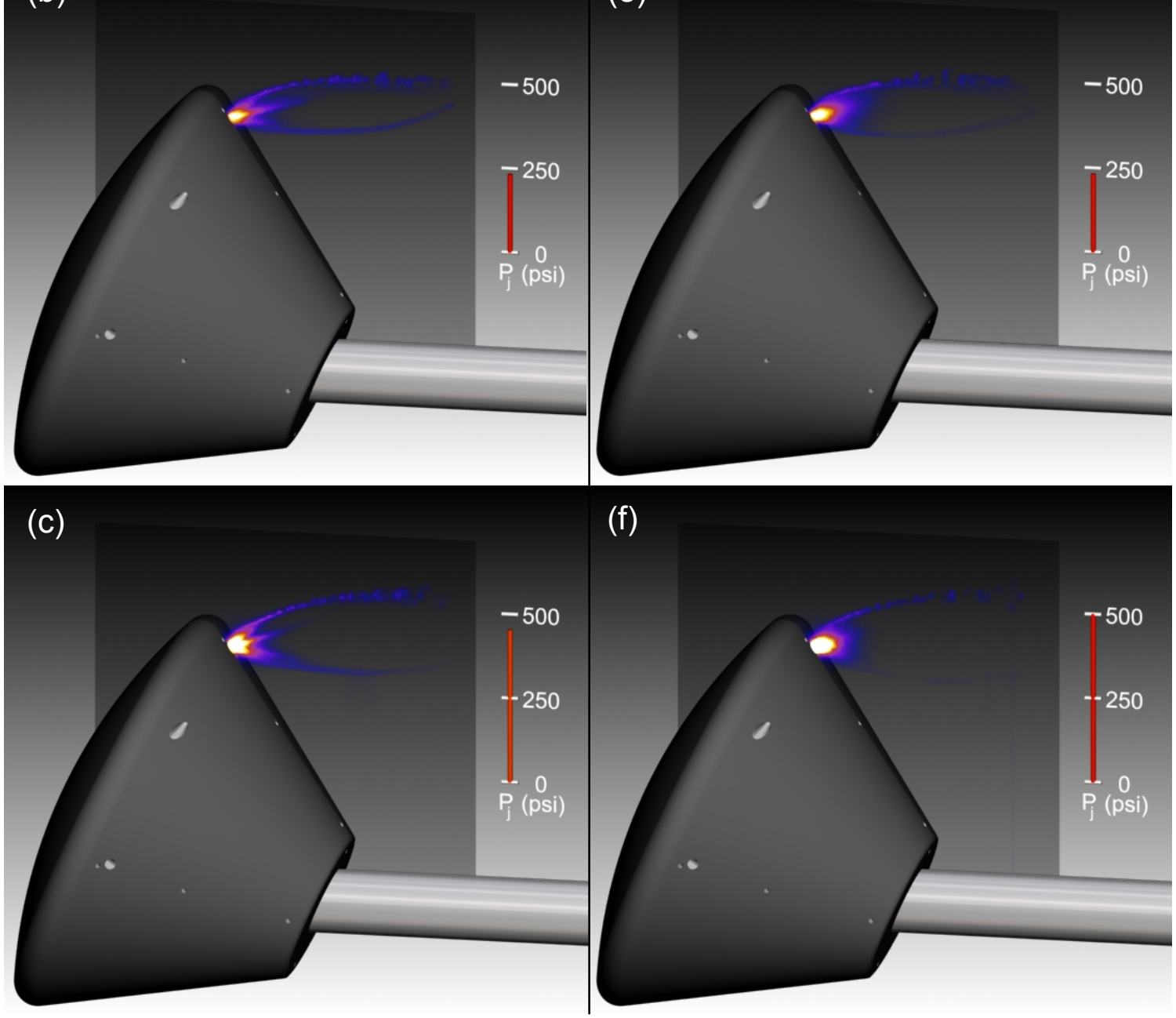

(f)

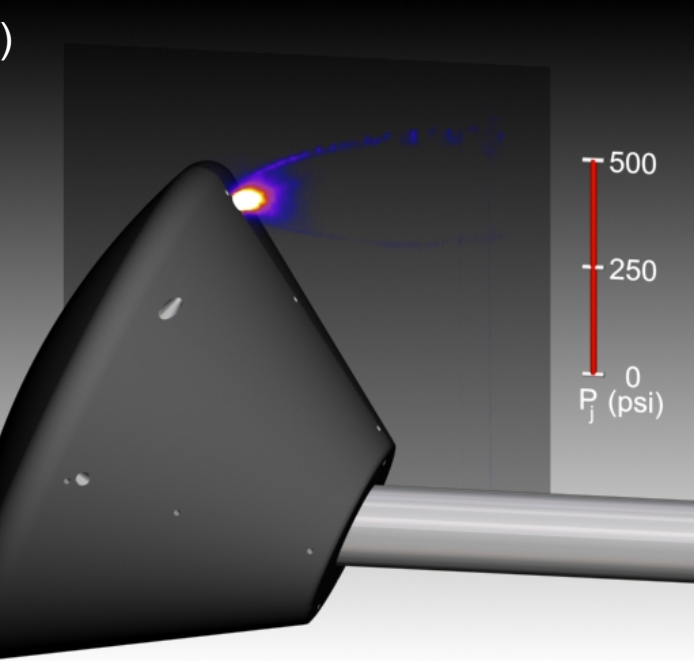

Figure A3: NO PLIF visualizations of RCS jet flows for flow into gas flowing at Mach 10, low Reynolds number condition: single-shot images. The tunnel stagnation pressure was $\mathrm{P}_{\mathrm{o}}=350 \mathrm{psi}$. The left column is for the bell nozzle while the right column is for the cone nozzle. The jet pressures are indicated by the bar graph. The color of the bar in the graph is insignificant. 

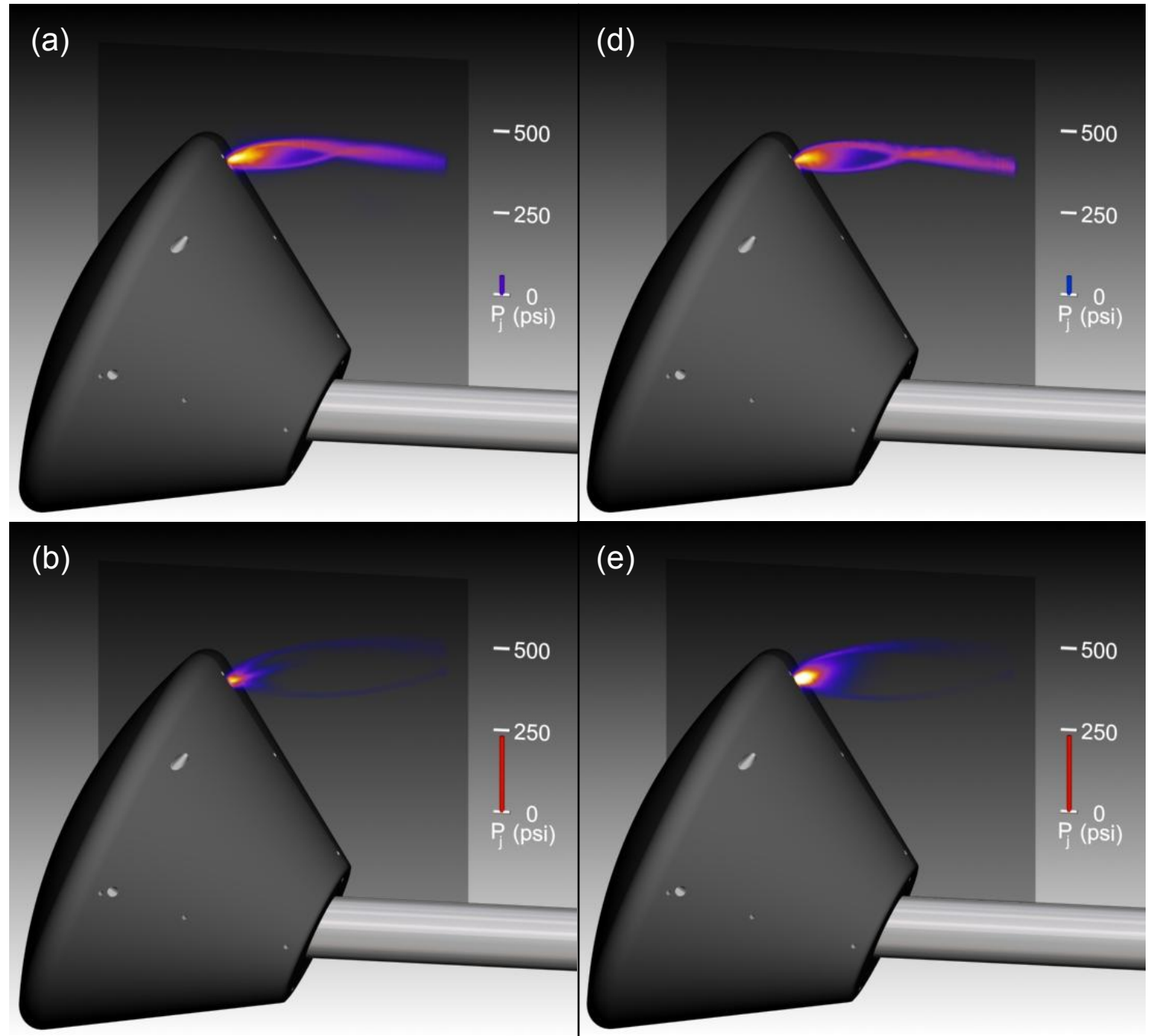

(e)

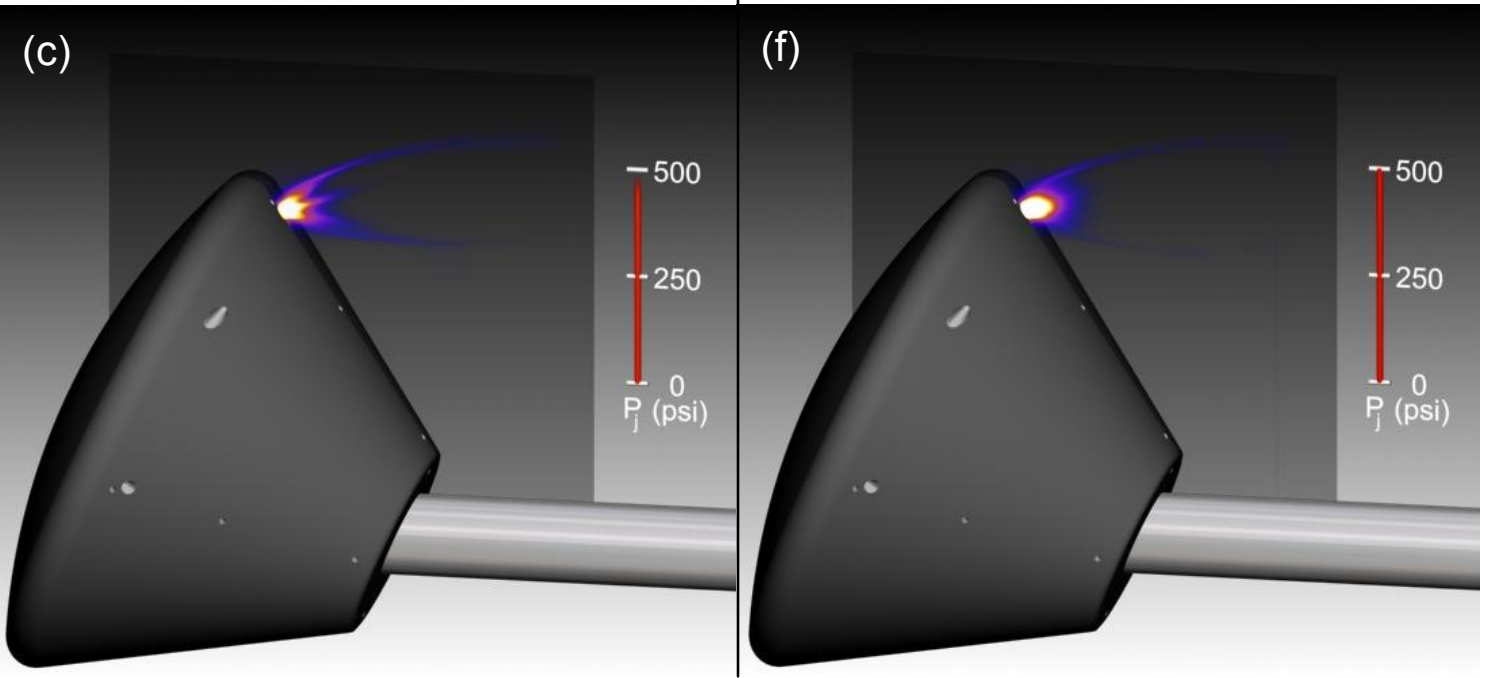

Figure A4: NO PLIF visualizations of RCS jet flows for flow into gas flowing at Mach 10, low Reynolds number condition: averaged images. The tunnel stagnation pressure was $P_{0}=350$ psi. The left column is for the bell nozzle while the right column is for the cone nozzle. The jet pressures are indicated by the bar graph. The color of the bar in the graph is insignificant. 

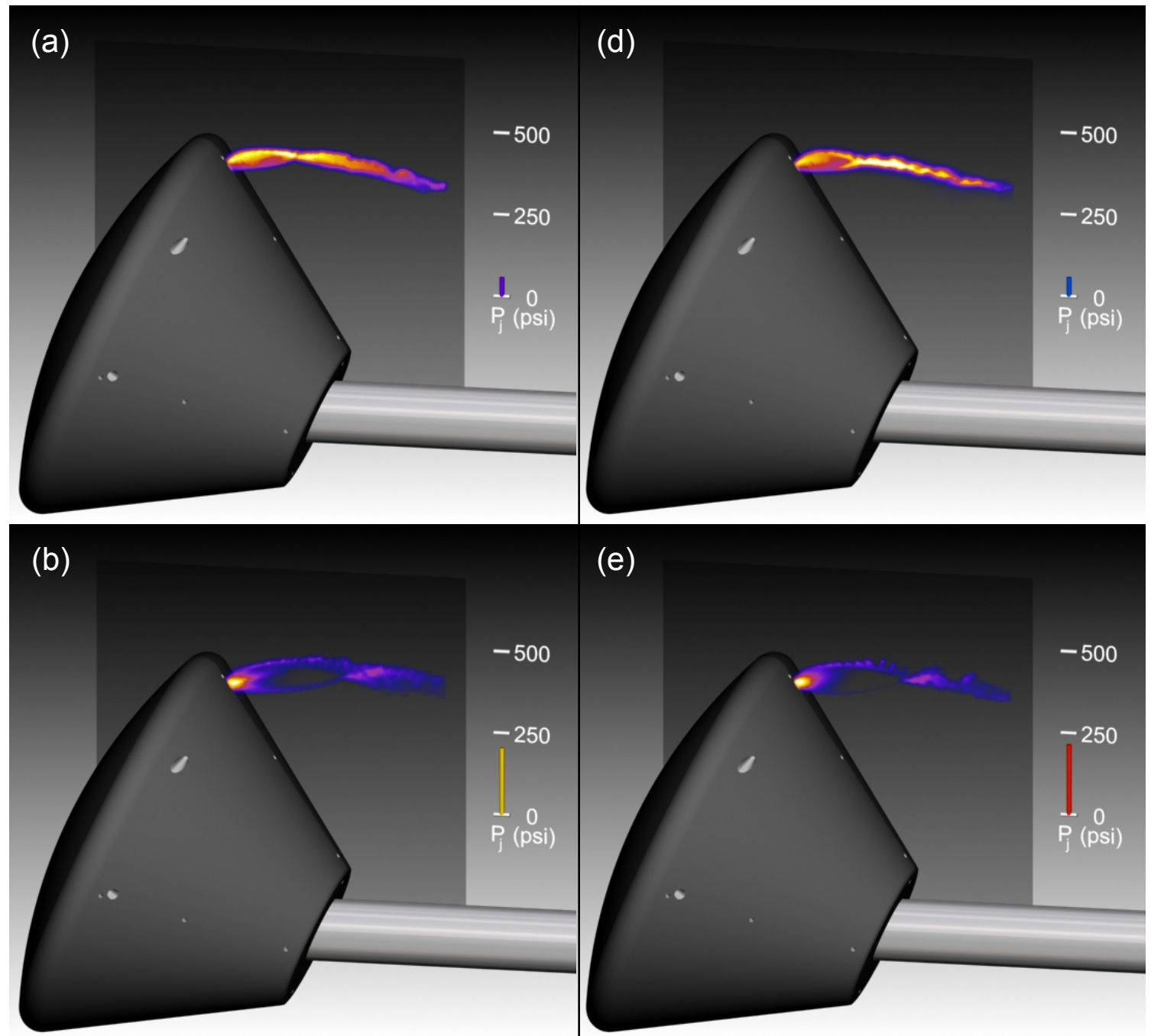

(e)

e)

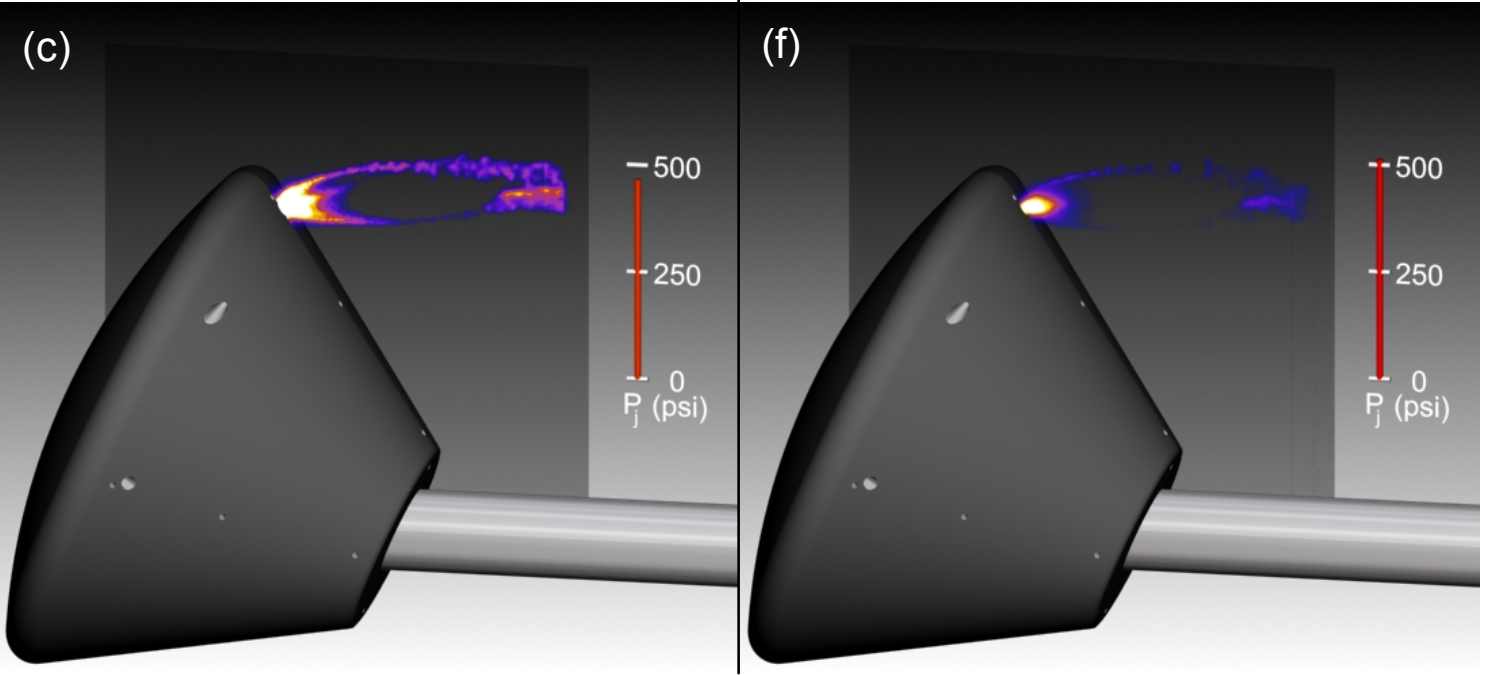

Figure A5: NO PLIF visualizations of RCS jet flows for flow into gas flowing at Mach 10, high Reynolds number condition: single-shot images. The tunnel stagnation pressure was $P_{o}=1300$ psi. The left column is for the bell nozzle while the right column is for the cone nozzle. The jet pressures are indicated by the bar graph. The color of the bar in the graph is insignificant. 

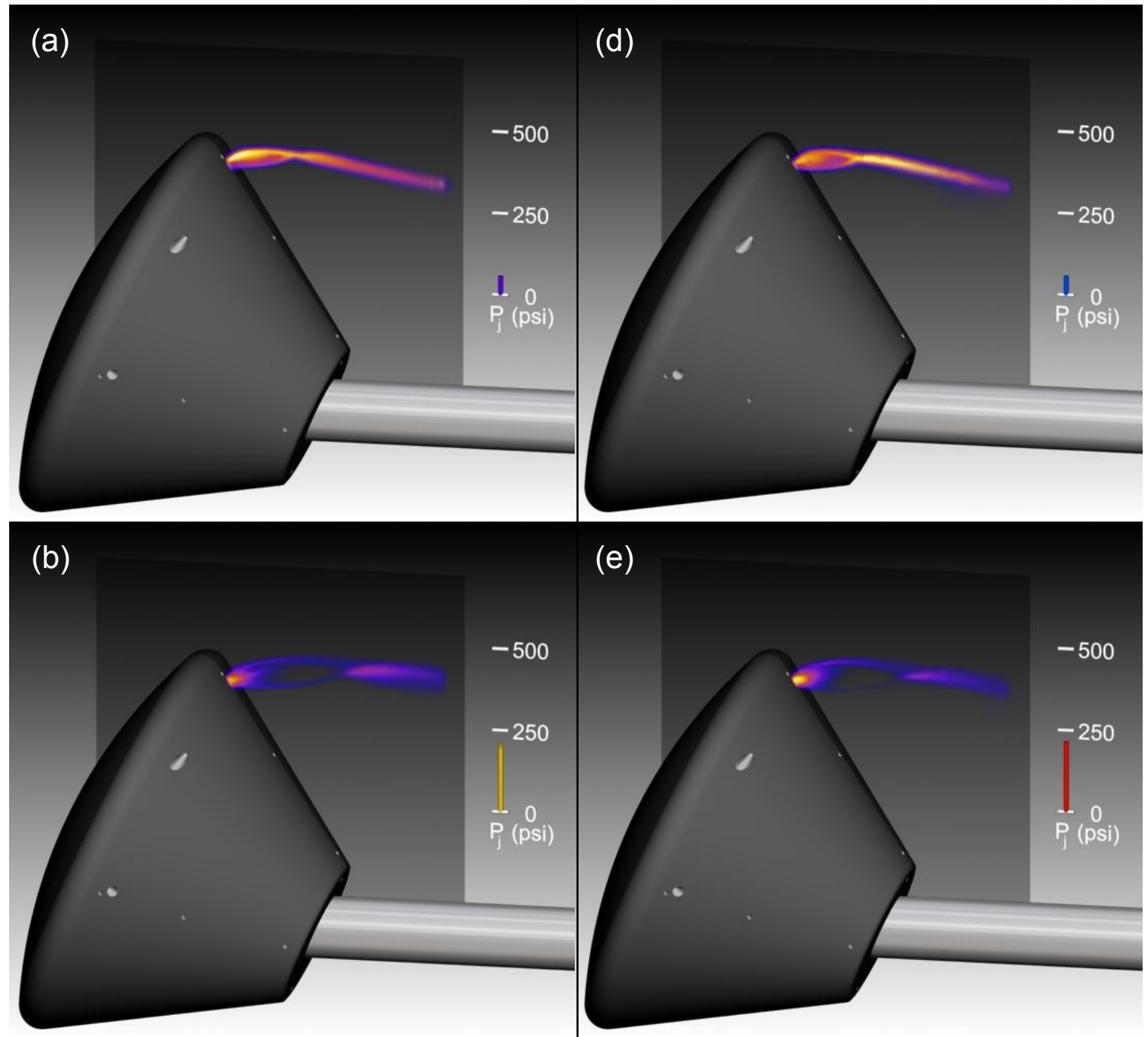

(e)

)

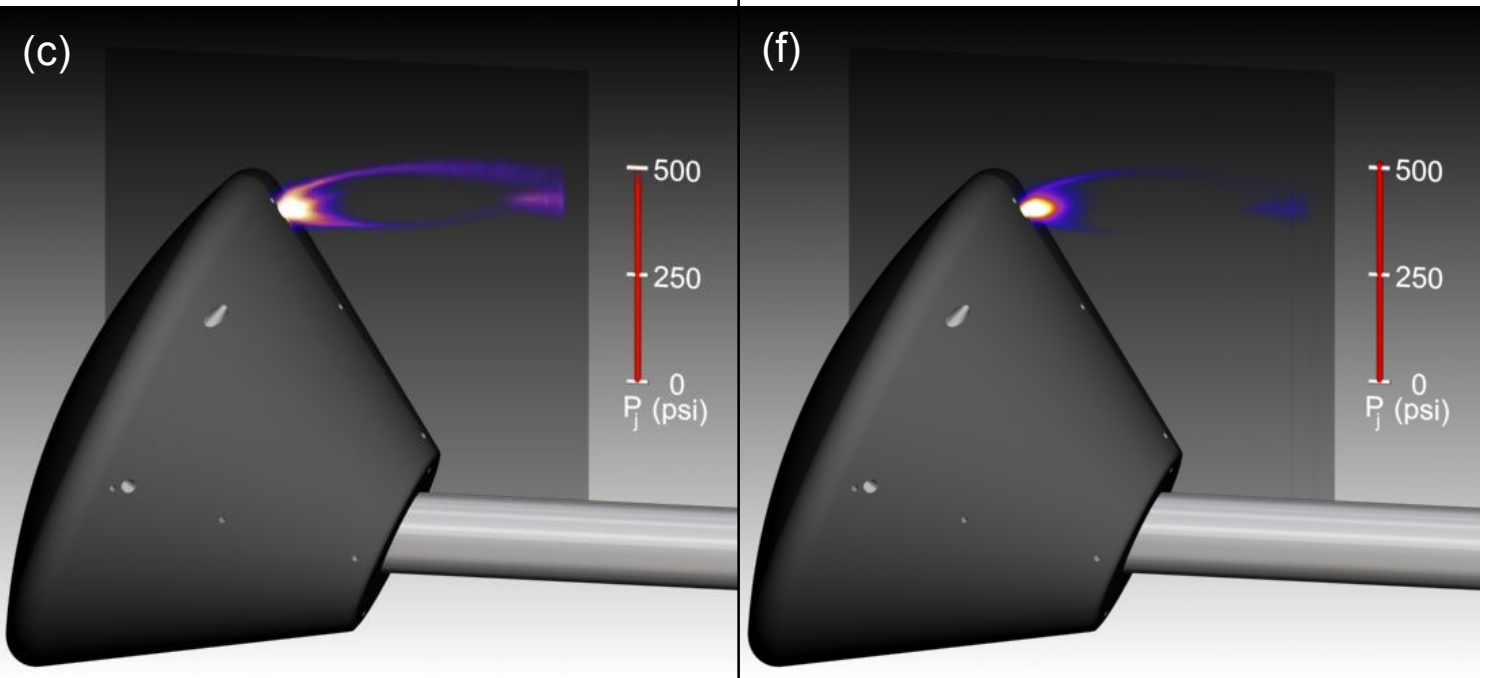

Figure A6: NO PLIF visualizations of RCS jet flows for flow into gas flowing at Mach 10, high Reynolds number condition: averaged images. The tunnel stagnation pressure was $P_{o}=1300$ psi. The left column is for the bell nozzle while the right column is for the cone nozzle. The jet pressures are indicated by the bar graph. The color of the bar in the graph is insignificant. 